\title{
Differences between the 2018 and 2019 stratospheric polar vortex split events
}

Article

Accepted Version

Butler, A. H., Lawrence, Z. D., Lee, S. H., Lillo, S. P. and Long, C. S. (2020) Differences between the 2018 and 2019 stratospheric polar vortex split events. Quarterly Journal of the Royal Meteorological Society, 146 (732). pp. 3503-3521. ISSN 1477-870X doi: https://doi.org/10.1002/qj.3858 Available at https://centaur.reading.ac.uk/91388/

It is advisable to refer to the publisher's version if you intend to cite from the work. See Guidance on citing.

Published version at: http://dx.doi.org/10.1002/qj.3858

To link to this article DOI: http://dx.doi.org/10.1002/qj.3858

Publisher: Royal Meteorological Society

All outputs in CentAUR are protected by Intellectual Property Rights law, including copyright law. Copyright and IPR is retained by the creators or other copyright holders. Terms and conditions for use of this material are defined in the End User Agreement.

\section{www.reading.ac.uk/centaur}

\section{CentAUR}

Central Archive at the University of Reading 
Reading's research outputs online 


\title{
Differences between the 2018 and 2019 stratospheric polar vortex split events
}

\author{
Amy H. Butler ${ }^{1 *}$ | Zachary D. Lawrence ${ }^{2,3 *}$ | Simon H. \\ Lee $^{4 *}$ | Samuel P. Lillo ${ }^{2,3 *}$ | Craig S. Long ${ }^{5 *}$
}

\footnotetext{
${ }^{1}$ NOAA Chemical Sciences Laboratory, 325 Broadway, Boulder, Colorado 80305

${ }^{2}$ Cooperative Institute for Research in Environmental Sciences (CIRES), University of Colorado, Boulder, Colorado 80309

${ }^{3}$ NOAA Physical Sciences Laboratory, 325 Broadway, Boulder, Colorado 80305

${ }^{4}$ Department of Meteorology, University of Reading, Reading, UK, RG6 6BB

${ }^{5}$ NOAA National Centers for Environmental Prediction (NCEP) Climate Prediction Center, 5830 University Research Drive, College Park, Maryland 20740

Correspondence

Amy $\mathrm{H}$. Butler, CIRES and NOAA CSL,

Boulder, CO, 80305, USA

Email: amy.butler@noaa.gov

\section{Funding information}

Natural Environment Research Council, Grant/Award Number: NE/L002566/1
}

Two recent occurrences in February 2018 and January 2019 of a dynamic split in the Northern Hemisphere stratospheric polar vortex are compared in terms of their evolution and predictability. The 2018 split vortex was associated with primarily wavenumber-2 wave forcing that was not well predicted more than 7-10 days ahead of time, and was followed by persistent coupling to the surface with strong weather impacts. In 2019 the vortex was first displaced by slow wavenumber-1 amplification into the stratosphere, which was predictable at longer lead times, and then split; the surface impacts following the event were weaker. Here we examine the role of large-scale climate influences, such as the phase of the El Niño-Southern Oscillation, the Quasibiennial Oscillation and Madden-Julian Oscillation, on the wave forcing, surface impacts, and predictability of these two events. Linkages between the forecast error in the stratospheric polar vortex winds with the forecast error in the Quasi-biennial Oscillation and Madden-Julian Oscillation are examined.

\section{KEYWORDS}

polar vortex, stratosphere, teleconnections, prediction, sudden stratospheric warming, stratosphere-troposphere coupling

\footnotetext{
*Equally contributing authors.
} 


\section{1 | INTRODUCTION}

Disruptions of the wintertime Northern Hemisphere (NH) stratospheric polar vortex, marked by rapidly warming temperatures and a reversal of the zonal-mean zonal winds from westerly to easterly, occur on average about every other year (Butler et al., 2017). These so-called "sudden stratospheric warmings" (SSWs) involve the displacement of the vortex off the pole, the split of the vortex into two vortices, or some combination of the two (Charlton and Polvani, 2007). These dramatic events $10-50 \mathrm{~km}$ above the Arctic are increasingly recognized as being potential sources of sub-seasonal to seasonal (S2S) predictability of wintertime weather (e.g., Butler et al., 2019; Domeisen et al., 2020a).

Two recent SSWs occurred on February 122018 and January 22019 (based on the reversal of the daily-mean 10 $\mathrm{hPa} 60^{\circ} \mathrm{N}$ zonal-mean zonal wind in ERA-Interim reanalysis). In 2018 the vortex abruptly split in two, while in 2019 the vortex was first displaced and then split (Rao et al., 2019). While both disruptions eventually resulted in a split vortex, there were important differences in how they evolved, their predictability, and their ultimate influence on the troposphere in the following weeks (Karpechko et al., 2018; Rao et al., 2018, 2019, 2020). For example, while the 2018 SSW was predicted at lead times of 10 days or less (Lee et al. (2019); typical for mid-winter SSWs, see Domeisen et al. (2020b)), the 2019 SSW could be predicted more than a week beyond that (Rao et al., 2020). This enhanced predictability was linked to the ability of the S2S prediction systems to largely capture planetary-scale (wavenumber 1) wave driving in mid-December 2018, weeks prior to the 2019 split vortex (Rao et al., 2019).

Another difference in the SSWs was that while the 2018 event was followed by the canonical weather pattern associated with the negative phase of the Northern Annular Mode (NAM) for up to 2 months (Greening and Hodgson, 2019), the 2019 event was followed by weaker and shorter-lived stratosphere-troposphere coupling, despite the split vortex persisting for an extended period of time (Lee and Butler, 2019). The stronger amplitude of stratospheric wind reversal in 2018 was statistically linked to increased probability of downward coupling to the surface (Rao et al., 2020).

The contrasting characteristics in evolution and predictability may be related to differences in large-scale circulation patterns during these two winters (Rao et al., 2019). For example, in 2018 the tropical Pacific was in a moderate La Niña state, while in 2019 there was a moderate El Niño. In general, poleward-propagating tropospheric planetaryscale (i.e., wavenumbers $k=1-3$ ) "wave trains", typically forced by tropical convective heating associated with the El Niño-Southern Oscillation (ENSO) or the Madden-Julian Oscillation (MJO), can linearly interfere with the climatological extratropical wave pattern (Domeisen et al., 2019; Garfinkel et al., 2012a). When this interference is constructive, these large-scale waves can amplify into the extratropical stratosphere, leading to a weakening of the polar vortex (Smith and Kushner, 2012; Fletcher and Kushner, 2013). These tropically-forced wave-trains can also modulate patterns in the extratropical troposphere that precede SSWs (Barriopedro and Calvo, 2014). These so-called precursor patterns are often different for split and displacement vortex events (Garfinkel et al., 2010; Cohen and Jones, 2011; Attard et al., 2016).

In the tropical stratosphere, the Quasi-biennial Oscillation (QBO) can also alter where vertically-propagating waves will break and deposit their momentum in the stratosphere. While the mechanism coupling the tropical stratospheric winds to the polar vortex is still uncertain (Garfinkel et al., 2012b; Anstey and Shepherd, 2014; White et al., 2015), one possibility is that the QBO changes the location of the subtropical critical line, beyond which the wind is easterly and where quasi-stationary planetary scale waves cannot propagate (Charney and Drazin, 1961). This mechanism, termed the Holton-Tan effect, leads to changes in wave momentum convergence, driving an associated mean meridional circulation that weakens the polar vortex and increases the likelihood of mid-winter SSWs during the easterly QBO phase (Holton and Tan, 1980). Lu et al. (2020) also find evidence that the QBO is associated not only with changes in the location of wave breaking but also with changes to wave structure, with greater wavenumber-1 disturbance of the polar vortex in the easterly QBO phase. In general, S2S prediction systems do not intrinsically simulate 
the QBO, but are able to persist the initialized tropical stratospheric wind conditions for a couple of weeks before degrading towards model climatology (typically a weak easterly state) (Butler et al., 2016; Garfinkel et al., 2018).

The two split polar vortex events in February 2018 and January 2019 were preceded by conditions with different phases of the QBO and ENSO, as well as differently phased but active periods of MJO evolution. These differences in the large-scale climate patterns, and how well prediction systems captured their influences on stratospheretroposphere coupling, likely had implications for the predictability of these events. Here we describe the evolution of the two events in Section 3.1 and their differences in predictability in Section 3.2. We then quantify how errors in the QBO and MJO forecasts in particular contributed to differences in the predictability of these major SSWs in Section 3.3.

\section{DATA AND METHODS}

We use daily-mean fields from the ERA-Interim reanalysis (Dee et al., 2011) to describe the evolution of the atmosphere and sea surface temperatures in Section 3.1 and for forecast verification in Section 3.2-3.3. Daily anomalies were computed by removing a daily climatology calculated as the mean value of each calendar day over the 1979-2018 period. The Northern Annular Mode (NAM) index was calculated at each pressure level by computing deseasonalized daily-mean geopotential heights averaged over $65-90^{\circ} \mathrm{N}$ with global-mean geopotential height anomalies removed (Gerber and Martineau, 2018). The resulting time series are normalized to have unit variance, and multiplied by 1 such that a negative NAM index denotes an anomalously weak polar vortex (and vice versa). The QBO index is described by the first and second time-extended empirical orthogonal functions (EOFs) of 30-day mean tropical $\left(5^{\circ} \mathrm{S}\right.$ $5^{\circ} \mathrm{N}$ ) zonal winds in the layer from $10 \mathrm{hPa}$ to $70 \mathrm{hPa}$ (using ERA-40 reanalysis back to 1960 to extend the historical data). Following Fraedrich et al. (1993) and Wang et al. (1995), the time-extended matrix is built using a sliding window of fifteen 30-day periods.

The MJO index (the Real-time Multivariate MJO, or RMM) is calculated as in Wheeler and Hendon (2004) and is provided by the Australian Bureau of Meteorology [http://www. bom. gov . au/climate/mjo/graphics/rmm. 74toRealtime . txt]. Bivariate root mean square error (RMSE) of the MJO forecasts for the S2S prediction systems in Section 3.3 is calculated following Rashid et al. (2011). The amplitude of ENSO is determined from the National Centers for Environmental Prediction (NCEP) Climate Prediction Center Oceanic Niño Index based on ERSSTv 5 sea surface temperatures [https://origin.cpc.ncep.noaa.gov/products/analysis_monitoring/ensostuff/ONI_v5.php].

In Section 3.2-3.3, we use real-time forecasts and hindcasts from the Subseasonal to Seasonal (S2S) project database (Vitart et al., 2017). We consider eight different prediction systems (CMA, ECCC, ECMWF, JMA, KMA, CNRM, NCEP, and UKMO). These prediction systems are all initialized at different frequencies and provide forecasts out to 4-6 weeks. They also have different reforecast periods. The details of the prediction systems used in our analysis, including ensemble size, forecast length and frequency are provided in Supporting Information (Table S1 and S2). Note that JMA and ECCC do not provide a T+Oh forecast; we have noted in figure captions where forecasts from these systems are shifted by 1 day relative to other systems. We bias-correct the model forecasts by subtracting the initialization date and lead-time dependent biases with respect to the ERA-Interim climatology, where the biases are determined using the full hindcast dataset available for each model. We note here limitations of this method: the bias correction method assumes that biases can be linearly removed, which may not be accurate especially during extreme vortex events; and determining the biases is dependent on the reforecast climatology which can be noisy for periods of less than 20 years.

We also examine moment diagnostics calculated from NCEP CFSv2 data (Saha et al., 2014) in Section 3.2 to ex- 
amine the subseasonal prediction of the stratospheric vortex geometry. We specifically focus on the centroid latitude and aspect ratio diagnostics similar to that calculated in Seviour et al. (2013). We use bias-corrected $10 \mathrm{hPa}$ geopotential height fields to calculate the parameters of the best-fit ellipse to the geometrical shape of the polar vortex. These calculations differ from those in Seviour et al. (2013) only in that the moments calculations are not weighted by the geopotential heights within the vortex edge contour; this is done so that the distortion of the vortex is better represented as the relative sizes and strengths of the sister vortices evolve during the split events. The centroid latitude and aspect ratio provide compact information about the degree of displacement of the vortex, and the degree of stretch in the vortex, respectively. They thus provide insight into how and when CFSv2 predicted the specific geometrical evolution of the 2018 and 2019 vortex splits. Note we also do not impose any persistence criteria to classify the events, as done in Seviour et al. (2013), but instead show the diagnostics for each day. We also use a region segmentation algorithm to confirm when the contour representing the vortex edge separates into more than one distinct region (e.g., Lawrence and Manney, 2018).

\section{3 | RESULTS}

\section{1 | The evolution of the 2018 and 2019 polar vortex split events}

The 2017-2018 and 2018-2019 NH stratospheric polar vortices evolved in a similar way through mid-December (Figure 1a). In the 2017-2018 winter, the vortex weakened in December, re-strengthened into the new year, weakened briefly in the latter half of January, and then rapidly decelerated and reversed on 12 February 2018 in a major SSW. The vortex split into two sister vortices, with the larger lobe ending up over central Canada and the smaller lobe over Europe (Figure 1b). The dominance of the Canadian vortex following this split event is not common; usually the Siberian vortex is dominant (Matthewman et al., 2009). The anomalous stratospheric warming peaked over the Atlantic sector within days of the zonal-mean zonal wind reversal. The zonal wind reversal following the February 2018 SSW was large in amplitude and persistent, lasting through the month and setting daily records for minimum zonal-mean zonal wind speeds at $60^{\circ} \mathrm{N}$ and $10 \mathrm{hPa}$ for the period 1979-2019 in ERA-Interim. The vortex subsequently recovered, and the so-called "final warming" (the last reversal of the wintertime vortex to its easterly summer state) occurred on the climatological mean date of 15 April.

In the 2018-2019 winter, the vortex began to weaken in mid-December, ending with a major SSW on January 2 2019. This zonal wind reversal also set daily records for minimum zonal-mean zonal wind speeds for the 19792019 period, though the amplitude of the reversal was not as large as for the February 2018 event (Lee and Butler, 2019). In this case, the vortex first displaced over the North Atlantic region, warming the polar stratosphere; after the vortex split, the sister vortices ended up over Europe and eastern Canada (Figure 1c). These lobes of the disrupted vortex persisted in these locations with nearly equivalent size for three weeks after the SSW (Figure S1), and stayed split even after the zonal-mean zonal winds returned to westerly. After the SSW, the vortex radiatively recovered, then continued to intensify, leading to daily records for maximum zonal-mean zonal wind intensity in March 2019. Following this vortex strengthening, the vortex decelerated, ending in a final warming slightly later than average on 23 April (Lee and Butler, 2019).

While for both SSWs the polar vortex split, with one lobe of the vortex over Eurasia and the other over North America, both the drivers and the impacts of these events were actually quite different. Figure 2 shows the sea surface temperature (SST) and $500 \mathrm{hPa}$ geopotential height anomalies in the month prior to the 2018 and 2019 vortex splits, respectively. In the winter of 2017-2018, a La Niña state prevailed (the DJF Oceanic Niño index was $-0.9^{\circ} \mathrm{C}$ ), with anomalously cold SSTs over the eastern and central tropical Pacific and tropical Indian Ocean. Opposite-signed tropical 
Pacific SST anomalies emerged the following winter of 2018-2019, with El Niño conditions (the DJF Oceanic Niño index was $+0.8^{\circ} \mathrm{C}$ ). The pattern of $500 \mathrm{hPa}$ height anomalies in the 30 days prior to the SSWs are at least partially related via teleconnections to the different tropical Pacific conditions that were present in each winter. La Niña is canonically associated with an anomalous ridge over the Aleutians and a negative Pacific-North American (PNA)-like pattern over North America, and El Niño with an anomalous Aleutian low and a positive PNA-like pattern (Deser et al., 2017).

The canonical La Niña teleconnection pattern was apparent in the month prior to the February 2018 SSW (Figure 2a), with some differences from the composite pattern: the anomalous Aleutian ridge was shifted northwest, the anomalous western North American trough was largely absent, and the ridging over the southeastern US was shifted northward. Persistent Aleutian blocking, mostly during La Niña winters, is a tropospheric precursor to SSWs, particularly split vortex events (Martius et al., 2009; Castanheira and Barriopedro, 2010; Barriopedro and Calvo, 2014; Cohen and Jones, 2011; Bancalá et al., 2012). Indeed, in the month prior to the February 2018 SSW, at least three strong poleward eddy heat flux events $\left(40-80^{\circ} \mathrm{N}, 300 \mathrm{hPa}\right)$ occurred (Figure 3; positive or poleward meridional heat flux is a proxy for vertically propagating waves from the troposphere to stratosphere). These predominantly $k=2$ wave pulses, associated with anomalous ridging over the Aleutians and also the Ural region (Martius et al., 2009), have been found to "precondition" the vortex, similar to other historical SSWs (Lawrence and Manney, 2020). The $k=2$ eddy heat fluxes set 2-3 new daily record highs at $300 \mathrm{hPa}$ in the month prior to the SSW (Figure 3b). The total eddy heat fluxes at $300 \mathrm{hPa}$ also set daily record highs around 13-14 January 2018 and in the 2-3 days prior to the SSW (Figure 3b). The daily record-breaking values of eddy heat flux at $10 \mathrm{hPa}$ (Figure 3a) in the week leading up to the SSW are likely a manifestation of the amplified $k=2$ pattern from the surface to $10 \mathrm{hPa}$ as the vortex splitting occurred (Birner and Albers, 2017; White et al., 2019; de la Cámara et al., 2019).

The canonical El Niño teleconnection was apparent prior to the 2019 SSW as an anomalous Aleutian low, another "precursor pattern" for SSWs (Figure 2b; Garfinkel et al. (2010); Bao et al. (2017)). While there were two noticeable $k=2$ eddy heat flux events in mid-November and early December, the vortex was primarily perturbed by a substantial but relatively slow amplification of $k=1$ eddy heat fluxes associated with the anomalous Aleutian low and Ural blocking high. The increase in $k=1$ eddy heat flux activity began in early to mid-December (Figure 3c,d), as the polar vortex was displaced off the pole. It is interesting to note that historically EI Niño SSWs are associated with more $k=1$ amplification compared to La Niña SSWs (Barriopedro and Calvo, 2014). The $k=1$ eddy heat fluxes at $300 \mathrm{hPa}$ and $10 \mathrm{hPa}$ set daily record highs in the two weeks prior to the 2019 SSW (Figure 3c,d). Finally, note that a strong $k=3$ pulse, setting a new daily record high at $300 \mathrm{hPa}$ (Figure 3d), occurred just days before the 2019 SSW (Rao et al., 2019).

The differences in wave activity in the 10 days before each SSW is highlighted in Figure 4. In 2018 (Figure 4a,b), the $k=2$ pattern was nearly barotropic (vertically-stacked from the surface to the mid-stratosphere), a feature common to split vortex events (Esler and Scott, 2005; Matthewman et al., 2009). The amplitude of $k=2$ exceeded $k=1$ from roughly 500-30 hPa and was well above climatology from 500-1 hPa. In comparison, in 2019 (Figure 4c,d), there was a strongly baroclinic (westward tilting with height) predominantly $k=1$ pattern. This anomalous wave pattern projected well onto the climatological wave pattern, suggesting constructive linear interference, which would allow amplification into the stratosphere (Smith and Kushner, 2012). Note also that in 2019, the amplitude of $k=2$ was below climatology throughout the atmospheric column, while $k=3$ was above climatology from the surface to $30 \mathrm{hPa}$ and matched $k=1$ amplitudes in the troposphere (see also Figure $3 \mathrm{~d}$ ). While disruptions of the polar vortex have only rarely been linked to $k=3$ activity (Shi et al., 2017), we think there are two potential explanations for its presence here. One possibility is that the $k=3$ pattern manifested as anomalous Pacific, Atlantic, and Ural blocking highs (Figure 4c), in a similar manner to the $k=2$ pattern in 2018 (Figure 4a) but with enhanced sinuosity. As the vortex displaced over the Atlantic sector, the Atlantic blocking high in particular may have helped to pull the vortex apart from below (Woollings et al., 2010, 
Figure S1). Another possibility is that nonlinear interactions between large-scale waves and the stratospheric basic state, as the vortex first displaced off the pole and then split, introduced a substantial $k=3$ component (Smith, 1983).

We also note that the downward influence following the SSW differed in 2018 and 2019. Both SSWs had a similar persistence of the zonal-mean zonal wind reversal in the stratosphere (19 days in 2018 and 21 days in 2019), though the magnitude of the reversal, which was roughly $-24 \mathrm{~m} / \mathrm{s}$ in 2018 and only $-10 \mathrm{~m} / \mathrm{s}$ in 2019 (Lee and Butler, 2019), might have played a role in the subsequent downward coupling (Karpechko et al., 2017; Rao et al., 2020). In particular, in 2018, the developing anomalous high pressure over the polar stratosphere had a downward influence that reached the troposphere within a week (Figure 5a). The anomalously high geopotential height anomalies over the Arctic were associated with an equatorward shift of the North Atlantic storm track and a negative NAM that persisted from late February to mid-March. Significant winter storms, such as the "Beast from the East", impacted Europe in late February (Greening and Hodgson, 2019); and as the North Atlantic blocking retrograded westward over Greenland in March (Figure S1), the northeastern United States also saw much colder weather and a surge of nor'easter extratropical cyclones (https://www.ncdc.noaa.gov/sotc/national/201803). The stratospheric polar vortex did not reform until March.

In 2019, strongly positive polar cap geopotential anomalies at $10 \mathrm{hPa}$, or the negative phase of the stratospheric NAM, were observed 10-12 days prior to the zonal wind reversal (Figure 5b). In the troposphere, anomalous and retrograding North Atlantic blocking was apparent, as in 2018, but the blocking grew weaker in the weeks following the SSW rather than stronger, and the impacts from the SSW did not project strongly onto the North Atlantic Oscillation (the regional manifestation of the NAM). Note that the NAM at $1000 \mathrm{hPa}$ did change to its negative phase from mid-January to early February, despite the fact that the free troposphere was in a positive NAM state for most of that period (Figure $5 \mathrm{~b}$ ). It has been previously noted that the surface response to anomalous stratospheric forcing is amplified compared to the troposphere (Baldwin and Thompson, 2009; Domeisen et al., 2020a). Nonetheless, the stratosphere-troposphere coupling following the SSW was not particularly strong nor persistent, with few notable impacts except perhaps the tropospheric "polar vortex" event that led to record cold in the central United States in late January (which was vertically well-aligned with the lobe of the stratospheric polar vortex over central Canada), followed by a week of anomalous cold over the eastern US in early February.

In essence, both the upward (troposphere to stratosphere) and downward (stratosphere to troposphere) coupling were quite different for these two events. The 2018 SSW was driven by primarily $k=2$ eddy heat fluxes associated with barotropic blocking patterns, and resulted in a persistently negative phase of the NAM and cold weather outbreaks. The 2019 SSW was preceded by slow and steady amplification of $k=1$ that first displaced the vortex before it split, and resulted in strong downward coupling to the tropopause that only briefly translated to typical surface impacts of a SSW. It should be noted that in the historical record, split polar vortex events have been observed to follow both $k=1$ and $k=2$ tropospheric precursor patterns (Bancalá et al., 2012), with the precursor pattern strongly tied to the phase of ENSO (Barriopedro and Calvo, 2014), in agreement with the 2018 and 2019 cases here. Additionally, irrespective of ENSO phase, both SSWs were preceded by strong anomalous ridging over the Ural mountains in northwestern Eurasia (also apparent in Figure 2 and Figure S1). Previous studies have noted the Ural blocking high as an important driver of increased upward-propagating wave activity (Garfinkel et al., 2010; Karpechko et al., 2018; Peings, 2019).

Other large-scale circulation patterns such as the QBO and the MJO may have influenced these two events. Figure 6a shows polar vortex weakening events at $60^{\circ} \mathrm{N}$ and $10 \mathrm{hPa}$ plotted in the phase space of the QBO, as described by the first and second time-extended EOFs of 30 -day mean tropical $\left(5^{\circ} \mathrm{S}-5^{\circ} \mathrm{N}\right)$ zonal winds in the layer from $10 \mathrm{hPa}$ to $70 \mathrm{hPa}$. The light gray lines trace the historical QBO values; note that the QBO amplitude does not vary much, with the obvious exception of the 2016 disruption (Coy et al., 2017). It is apparent that polar vortex weakenings tend to occur when the tropical stratospheric winds below roughly $30 \mathrm{hPa}$ are easterly (i.e., below the 
diagonal EOF1=EOF2 line; 42 events), relative to when the stratospheric winds below $30 \mathrm{hPa}$ are westerly (18 events). Both the February 2018 and January 2019 SSWs occurred in the top two QBO octants for most vortex weakenings. However the February 2018 event occurred during a period when the tropical winds at 50 hPa were weakly westerly (with strong easterlies above $40 \mathrm{hPa}$ ), whereas in January 2019 the tropical winds at $50 \mathrm{hPa}$ were easterly (with strong westerlies above $40 \mathrm{hPa}$ ); i.e., the QBO was roughly $180^{\circ}$ out of phase between the two events. The maximum daily $100 \mathrm{hPa} 45-75^{\circ} \mathrm{N}$ eddy heat flux anomaly in the 10 days prior to vortex weakening (shading of dots) generally corresponds with the magnitude of the polar vortex weakening (size of dots). There is some preference for preceding eddy heat flux anomalies to be enhanced for events occurring in phases with easterlies in the tropical stratosphere below $30 \mathrm{hPa}$ (Holton and Tan, 1980; Lu et al., 2020).

Like ENSO, the MJO can lead to poleward-propagating wave trains that shift longitudinally depending on where the anomalous tropical convection occurs (Hoskins and Karoly, 1981). Figure 6b shows MJO-polar vortex states for February 2018 and January 2019 in a historical context. Polar vortex weakenings at $60^{\circ} \mathrm{N}$ and $10 \mathrm{hPa}$ (dot size) and the minimum value of the $1000 \mathrm{hPa}$ NAM index in the following 45 days (shading), are plotted in the phase space of the RMM index. Note that only simultaneous relationships between the MJO and polar vortex strength are indicated here; other studies have suggested there is a 10-20 day lag between the MJO tropical forcing and extratropical and stratospheric impacts (Kang and Tziperman, 2017). Many SSWs have occurred when the MJO is inactive (i.e., within the unit circle on the phase space diagram). However, for both the February 2018 and January 2019 SSW, the MJO was active in phases 5-7 prior to the events, consistent with, e.g., Garfinkel et al. (2012a) and Liu et al. (2014).

Specifically, 15 days before the February 2018 SSW, enhanced tropical convection was evident over the western Pacific as the MJO hit near record amplitudes in phase 6-7 (Figure 6b). This phase of the MJO is typically followed 10-15 days later by enhanced extratropical eddy heat fluxes (Garfinkel et al., 2014) with polar vortex weakening (Garfinkel et al., 2012a). A week after the SSW, the MJO entered phase 8 which is associated with a negative NAO pattern (Lin et al., 2009; Henderson et al., 2016). Thus it is possible that the MJO played a significant role via its extratropical teleconnection in encouraging a North Atlantic blocking pattern by mid- to late February that was conducive to downward coupling from the stratosphere (Barnes et al., 2019). By early March 2018, the MJO signal in phase 2 had decayed; interestingly, this is also around when the mid-troposphere showed less coupling with the stratosphere (Figure 5), though the surface NAM stayed negative through mid-March. In comparison, prior to the January 2019 SSW, the MJO was entering phase 5-6. The MJO then moved quickly at low amplitude through phase 6-7, stalled in phase 8 in early January, decayed, and then re-emerged around 18 January in phases 4-5. Overall, the MJO was in a similar phase as 2018 but with weaker amplitude and faster decay to neutral state.

Figure $6 \mathrm{~b}$ indicates that the MJO phase may modulate the surface response following the polar vortex deceleration (Barnes et al., 2019). There is a preference for lower minimum NAM values in the 45 days following SSWs that occur in active (RMM magnitude $>1$ ) MJO phases 6-1 compared to phases 2-5 (the frequency of events with minimum NAM $<-2 \sigma$ is $12 / 19=0.63$ for phases $6-1$, and $7 / 20=0.35$ for phases $2-5$ ). This suggests that the MJO enhanced the likelihood of a more negative surface NAM response following both the February 2018 and January 2019 SSWs.

\subsection{The predictability of the 2018 and 2019 polar vortex splits}

In general, SSWs are not predictable more than 10-20 days in advance, though this can vary by individual event (Tripathi et al., 2014; Karpechko, 2018). Vortex splits are likely to be even less predictable than vortex displacements (Taguchi, 2015, 2018). The predictability of the 2018 SSW has been detailed in previous studies. Karpechko et al. (2018) found that S2S prediction systems forecast the 2018 SSW about 11 days in advance, and accurate prediction was linked to the ability of the models to correctly capture the location of anomalous Ural blocking (e.g., Figure 2). Rao 
et al. (2018) found similar timescales of predictive skill for the 2018 event. Lee et al. (2019) found that anticyclonic Rossby wave breaking in the North Atlantic, which was tied to the amplification of the Ural blocking high and $k=2$ in the stratosphere, was not well forecast and thus limited how soon prediction systems forecast the event. For the 2019 event, Rao et al. (2019) found predictive skill at up to 18 day lead times in the S2S prediction systems.

We use real-time forecasts of the S2S prediction systems to compare the prediction of the 2018 and 2019 vortex splits. We show the percent of ensemble members accurately detecting the first zonal-mean zonal wind reversal in the forecast within \pm 3 days of the observed SSW date (Figure 7a,c), and the percent of ensemble members that detect the first zonal wind reversal in the forecast outside this 3-day window (Figure 7b,d) for different S2S prediction systems. In 2018, most prediction systems had fewer than $75 \%$ of members accurately detecting the SSW until 10-13 days prior to the SSW. Models with poor stratospheric resolution, such as CMA, had even shorter predictability of about 7 days. However most of the prediction systems also showed increased probability (> 50\%) of a "false" SSW (mostly predicted to occur near the end of January, not shown) when initialized between January 7-20, during the period of record-setting upper tropospheric wave activity (Figure 3). In other words the models may have tried to break down the vortex too soon in response to this anomalous tropospheric eddy heat flux.

In 2019, the detection of the SSW was possible at longer lead times, with KMA, ECMWF, and UKMO prediction systems showing accurate detection of the SSW for forecasts initialized up to 15-22 days prior. However, other systems such as NCEP showed accurate detection at shorter lead times compared to the 2018 event (though the false alarm rate peaked in NCEP just before the peak in hit rate, suggesting NCEP predicted an SSW for forecasts initialized as early as Dec 11th, but not at the correct time). Across the prediction systems, there was a gradual increase in false alarms for forecasts initialized in the weeks prior to the event, likely tied to the gradual increase of $k=1$ amplitudes (Figure 3).

Note here we are showing detection rates using bias-corrected forecasts. The bias-correction affects primarily extended-range forecasts; a version of Figure 7 without bias correction is available in Supplemental Information (Fig S2) for comparison. We find at forecast times of greater than 10 days significant biases that can affect accurate prediction of stratospheric variability for some prediction systems. While Figure 7 accounts for these biases, we note that in particular CMA and NCEP CFSv2 have large (opposing) biases at forecast times of greater than 10 days during parts of the winter season. For example, NCEP is biased at extended-range (10-40 days) towards a weakerthan-observed vortex, particularly in early winter (Figure S3). On the other hand, CMA is biased at extended-range towards a stronger-than-observed vortex for initializations throughout the winter.

Given that the February 2018 SSW was a predominantly k=2 split vortex event while the January 2019 SSW first displaced by an amplifying $k=1$ before splitting, we investigate how well the NCEP CFSv2 predicted these differences in morphology. NCEP CFSv2 forecasts of polar vortex geometry are derived from $10 \mathrm{hPa}$ geopotential heights (Seviour et al., 2013). The calculation of the aspect ratio, which measures the elongation of the vortex (where larger aspect ratio means more elongation), and the centroid latitude, which designates the center latitude position of the vortex, is described in Section 2. Figure 8a,c shows the predicted vortex evolution for the February 2018 SSW. Here, individual ensemble-mean forecasts run diagonally, with increasing forecast day on the $y$-axis, so that forecast validation times line up in each vertical column. During the 2018 winter season, at forecast times beyond roughly 20 days, CFSv2 generally predicted a tendency for the vortex to become displaced to latitudes near and below $70^{\circ} \mathrm{N}$ by early February (Figure 8a), with little elongation (Figure 8c). Only for forecasts of less than 10-14 days was NCEP able to better capture both the observed center latitude of the vortex and the elongation of the vortex. The prediction system captured the observed vortex elongation that occurred between January 20-25 for forecast times of up to 10 days, which was also when a false SSW was forecast (Figure 7b); and only accurately predicted the observed split vortex (here defined as an aspect ratio greater than 2.4 ) for forecast times of less than 10 days. 
In contrast, for the 2019 SSW (Figure 8b,d), NCEP CFSv2 consistently and accurately predicted a displaced vortex to latitudes near and equatorward of $70^{\circ} \mathrm{N}$ by mid-December 2018 even up to 20 days in advance. However, the forecasts for the end of December into January strongly indicated the event would be a displacement, even for 5-20 day forecasts, as NCEP struggled to capture the elongation and split of the vortex. The difficulty in capturing the event evolution is likely related to failure of the models to capture the $k=3$ peak at longer forecast times (Rao et al., 2019). The observed split of the vortex, which occurred December 28 2018-January 2 2019, was only accurately reflected in the forecasts initialized at most a week ahead of time, even shorter lead times than in 2018.

Finally, we consider how well the large-scale surface response, as measured by the $1000 \mathrm{hPa}$ NAM index for days 10-30 following each SSW, was predicted by the S2S prediction systems' ensemble-mean (Figure 9). The observed NAM during this 20-day period was -1.23 standardized units following the $2018 \mathrm{SSW}$, but only -0.60 standardized units following the 2019 SSW (see Figure 5). For each SSW, we show how the forecast NAM response was verified for forecasts initialized two weeks prior to the event and then for the 10 days after the SSW occurred; gray dots indicate that the forecast value was within \pm 0.5 standard deviations of the ERA-Interim response. For most prediction systems, as expected, the forecast of the surface response is better predicted for initializations closer to the 10-30 day window following each SSW (i.e., at shorter lead times).

Prior to the 2018 SSW (Figure 9a), most prediction systems were suggesting a NAM response that was more positive than observed (blue shading), particularly when initialized in late January, when the forecasts backed off from a SSW occurring (Figure 7a). KMA and UKMO continued to underestimate the negative NAM response even in forecasts initialized after the SSW. In 2019 (Figure 9b), again most forecasts were suggesting a more positive NAM response than observed in the forecasts initialized prior to the event, though ECMWF showed little error in verification even in forecasts initialized on December 20th (and also had greater than $70 \%$ of members detecting the observed SSW, Figure 7c). Other prediction systems, such as UKMO and NCEP, continued to underestimate the negative NAM response until after the SSW occurred. CMA generally predicted too positive of a response prior to, and too negative of a response after, both the 2018 and 2019 SSW.

Note that the predicted NAM response has been bias-corrected in Figure 9. Without bias correction (Figure S4), CMA generally predicted too weak a NAM response while NCEP predicted a more negative NAM response than observed across almost all lead times in both 2018 and 2019. This is consistent with the strong vortex bias in CMA and the weak vortex bias in NCEP. The systematic bias correction thus has a substantial impact on verification following these events.

\subsection{Linking errors in the QBO and MJO forecasts to errors in polar vortex prediction}

Accurate extended-range (week 2-5) forecasts of polar vortex variability in the S2S prediction systems may be linked to their ability to simulate processes and teleconnections correctly. In this section, we examine the relationship of forecast errors in the QBO and MJO to errors in the polar vortex forecast leading up to the 2018 and 2019 SSWs. Throughout this section we use bias-corrected forecasts, but the results are the same if we use uncorrected forecasts. In 2018, the QBO at $50 \mathrm{hPa}$ was weakly westerly. Averaging over forecast-times for 4 initializations (or launch dates) prior to the SSW that are consistent across prediction systems (Figure 10a), we can see that although the S2S prediction systems were initialized with similar tropical stratospheric wind values (with the exception of JMA and ECCC), the forecast tropical winds degrade to an easterly state at $50 \mathrm{hPa}$ within 10 days for almost all systems. Models without an intrinsic QBO typically have weak climatological easterlies in the tropics (Butler et al., 2016). All systems thus show too easterly winds in the tropics at almost all forecast times; JMA and ECCC show the greatest errors at 20-30 day forecast times. 
A different situation was present in 2019 , when the QBO at $50 \mathrm{hPa}$ was easterly but more rapidly transitioning to neutral as westerlies descended from above (Figure 10c). The prediction systems degraded the initialized easterlies more rapidly than observed, so in this case, most of the systems had tropical winds that were too westerly compared to ERA-Interim. The one exception was NCEP which had too easterly winds at all forecast times. UKMO had the smallest errors at 10-30 day forecast times, while JMA had the largest errors at 20-30 day forecast times.

We examine the relationship between errors in the predicted tropical stratospheric winds for the 7-11 February 2018 validation dates and errors in the stratospheric polar vortex (SPV) for the 12-16 February 2018 validation dates (Figure 10b; following Rao et al. (2019)), for different forecast initialization dates. We might expect via the Holton-Tan relationship that a more easterly QBO error would be linked to a more easterly SPV error (i.e., a positive correlation). However, at first glance it appears the opposite is true in 2018; forecasts with more easterly QBO error had too strong of polar vortex winds. Upon further examination, we see that the amplitude of the relationship across the 4 launch dates shown ( $r=-0.31)$ is largely a reflection of the decreased error, particularly for polar vortex strength, at shorter lead-times. Only at the earliest launch date (18 January 2018, blue dots in Fig 10b) is the correlation of SPV error to QBO error significantly positive. The systems with the greatest easterly QBO error at 20-30 day forecast times, JMA and ECCC, also show the smallest (more easterly) SPV error for this launch date.

In 2019 (Figure 10d), because the 28 Dec-1 Jan QBO forecast error is mostly positive (i.e., the winds were too westerly compared to observed), the correlation with the 2-6 Jan SPV error is positive across all launch dates ( $r=0.38$ ). Again, the amplitude of the correlation across launch dates is a reflection of the reduced errors in the SPV at shorter lead-times. At the earliest launch date of December 6 (blue dots), the correlation is significantly positive as expected, and the systems with the more easterly QBO errors, NCEP and UKMO, also had the smallest (more easterly) SPV errors. Thus beyond 1-3 week forecast times, the biases in polar vortex winds and QBO winds may be linked as expected from the Holton-Tan relationship (Garfinkel et al., 2018).

Note that for individual launch dates less than 1-3 weeks prior to the SSWs, the relationship between errors in QBO and SPV is quite different for 2018 and 2019. Namely, the launch dates from 25 January-8 February 2018 all show significant negative correlations, whereas the launch dates from 13-27 December 2018 show insignificant correlations and disagree in sign. This suggests that prediction systems that better predicted the QBO in the week prior to the February 2018 SSW also better predicted the SPV, while in 2019 there was little gain for systems better predicting the QBO. The negative correlations in 2018 are particularly puzzling because they suggest the systems that predicted a more easterly QBO also predicted a more westerly SPV. We think it likely that these relationships are a reflection of some systems better predicting both the QBO state and the SPV state in 2018, rather than a causal linkage between the QBO and SPV errors at shorter lead-times.

We also consider links between the bivariate RMSE (Rashid et al., 2011) of the MJO forecasts and the error in both the SPV and NAM forecasts (Figure 11). Since the correlation across all 4 launch dates (shown in upper right corner of each panel) is largely a measure of the change in error in both SPV/NAM and MJO RMSE with shorter leadtimes, we instead focus on the correlations for each launch date separately. Considering first the relationship of MJO RMSE to the SPV error (Figure 11a,c), it is evident that in general, for most launch dates, there is little relationship between the RMSE of the predicted MJO for the week before the SSW and the error in the predicted SPV. This may be a reflection of the general underestimation of the observed MJO amplitude and slower eastward propagation in the extended range by the S2S systems (Vitart, 2017; Lim et al., 2018, see also Figure S5-S6 in Supporting Information), which may affect the MJO teleconnections and influence on the SPV. Or, it may be that we need to consider longerlagged relationships between the MJO error and SPV error; here we have selected validation periods a week apart to maximize the number of forecasts we can compare, but relationships between MJO and SPV have been found to be largest at 10-20 day lags (Kang and Tziperman, 2017). For launch dates closer to the 2018 SSW, there is a stronger 
positive relationship, showing models that had reduced MJO RMSE also had reduced error in the SPV forecasts, but these may not be causally linked.

Finally we examine the relationship of the MJO RMSE to errors in the NAM forecasts (Figure 11b,d). Here, we only consider the 4 prediction systems (CMA, ECMWF, NCEP, and UKMO) that have long enough forecasts to compare the error in NAM forecasts validated for the 22 Feb-14 Mar 2018 and 12 Jan-1 Feb 2019 periods (the same NAM forecasts shown in Figure 9) with the MJO RMSE validated the week prior to the observed SSW. Note that ECMWF will dominate these correlations because it has many more ensemble members than the other three. The overall correlation across launch dates is weak and insignificant, as the NAM error is not consistently smaller across prediction systems for shorter lead-times. In 2018, for the 29 January and 5 February launch dates, the relationship between the NAM error after the SSW and the RMSE of the MJO the week prior to the SSW is significantly negatively correlated. In particular, we note that ECMWF and UKMO both predicted too positive of 22 Feb-14 Mar NAM response for the 29 January and 1 February launch dates (Figure 9), despite having low RMSE for their MJO forecast, suggesting a well-predicted MJO did not mean a better NAM forecast in 2018. Only for the 8 Feb launch date is the lower MJO RMSE linked to lower NAM error, which may suggest the MJO helped induce the negative NAM once the SSW had occurred.

In 2019, no significant relationship between MJO RMSE and NAM error was found for any launch date except 27 December. Overall, Figure 11b,d suggests that the NAM error after the 2018 and 2019 SSW was not closely tied to the ability of the prediction systems to capture the MJO the week prior to the SSW.

\section{4 | CONCLUSIONS}

In this study, we performed an in-depth comparison between two split vortex events that occurred on February 12 2018 and January 2 2019. There were substantial differences in the evolution of these events, their surface impacts, and their predictability. Here, we have examined how those differences may have been tied to differences in largescale circulation patterns, such as ENSO, the MJO and the QBO, and their teleconnections.

The 2018 SSW was primarily a wavenumber-2 event preceded by anomalous Aleutian and Ural blocking highs, a tropospheric pattern which commonly precedes SSWs occurring in La Niña winters such as this one. However the $k=2$ forcing that ultimately split the vortex was predictable at timescales of less than 7-10 days. The 2018 SSW was followed by swift and persistent coupling to the surface, with substantial impacts on late winter weather over Europe and the eastern United States. The negative NAM response was generally under-predicted in amplitude by most prediction systems until the SSW occurred.

The 2019 SSW was instead a wavenumber-1 event, which first displaced the polar vortex over the North Atlantic before splitting. This SSW was preceded by an Aleutian low and a North Atlantic/Ural blocking high, which interestingly manifested as a strong wavenumber-3 forcing days before the vortex split. The moderate El Niño in the 2019 winter likely contributed to the persistent precursor pattern that led to the amplification of $k=1$ into the stratosphere, and ultimately to the SSW. Because this SSW was associated with a slow build-up of $k=1$, it was predictable at much longer lead-times, though the prediction systems only predicted the vortex would split (rather than displace) at lead times of less than a week. After this event, there was weaker coupling to the surface with only minor weather impacts. The predicted NAM response was still mostly too positive for the majority of prediction systems except for forecasts initialized after the SSW. To understand the differences in evolution and predictability on S2S timescales, we examined in particular how the QBO and MJO may have influenced these events and their impacts. While both SSWs occurred in phases of the QBO historically conducive to SSWs, the QBO was 180 degrees out of phase in 2018 and 2019. This 
difference in QBO state played a role in the forecast biases in S2S prediction systems. Namely, in 2018 the prediction systems were not able to maintain the weak westerly state at $50 \mathrm{hPa}$ and were biased easterly at all forecast times, while in 2019 they largely captured the easterlies at $50 \mathrm{hPa}$ but weakened too fast, so were biased westerly. Nonetheless, in both years for forecasts initialized more than 3 weeks from the SSW, a Holton-Tan relationship was apparent between the error in the QBO and the error in the SPV, with more easterly errors in the QBO significantly correlated to more easterly error in the SPV. A significant positive relationship for the February 2018 SSW was also seen between the MJO RMSE and the error in the SPV for launch dates less than 2 weeks prior to the SSW, and for the error in the NAM for the launch date closest to the SSW. On the other hand, for the 2019 SSW, little significant relationships were found between the RMSE of MJO forecasts and the error in the NAM or the error in the SPV.

While this is only a case study of two polar vortex events, and so statistical relationships cannot be inferred or confirmed, it demonstrates the large inter-event variability of SSW impacts and predictability (Gerber and Martineau, 2018). A substantial part of this variability may not be due to the morphology of the SSW itself as some studies suggest (Mitchell et al., 2013), but to other large-scale climate patterns in which the SSW evolves. While much understanding has been gained regarding why and how SSWs occur, further work remains on how we can better predict the stratosphere-troposphere coupling signal given the intrinsic variability of the large-scale circulation during any given SSW event.

\section{Supporting Information}

Table S1. Model versions used in the prediction analysis of the 2018 SSW.

Table S2. Model versions used in the prediction analysis of the 2019 SSW.

Figure S1. Evolution of the $10 \mathrm{hPa}$ geopotential height and temperature anomalies, and $500 \mathrm{hPa}$ geopotential height and surface temperature anomalies, from 21 days prior to 21 days after the 2018 and 2019 SSWs.

Figure S2. The non-bias-corrected version of Figure 7.

Figure S3. Biases in the NCEP CFSv2 prediction system.

Figure S4. The non-bias-corrected version of Figure 9.

Figure S5. MJO forecasts for 4 different launch dates prior to the February 2018 SSW.

Figure S6. MJO forecasts for 4 different launch dates prior to the January 2019 SSW.

\section{Acknowledgements}

S.H.L. acknowledges funding by the Natural Environment Research Council (NERC) via the SCENARIO Doctoral Training Partnership (NE/LO02566/1).

\section{references}

Anstey, J. A. and Shepherd, T. G. (2014) High-latitude influence of the quasi-biennial oscillation. Quarterly Journal of the Royal Meteorological Society, 140,1-21. URL: http://dx.doi.org/10.1002/qj. 2132.

Attard, H. E., Rios-Berrios, R., Guastini, C. T. and Lang, A. L. (2016) Tropospheric and Stratospheric Precursors to the January 2013 Sudden Stratospheric Warming. Monthly Weather Review, 144, 1321-1339. URL: https://doi.org/10.1175/MWRD-15-0175.1.

Baldwin, M. P. and Thompson, D. W. (2009) A critical comparison of stratosphere-troposphere coupling indices. Quarterly Journal of the Royal Meteorological Society, 135, 1661-1672. URL: http://doi . wiley.com/10.1002/qj .479. 
Bancalá, S., Krüger, K. and Giorgetta, M. (2012) The preconditioning of major sudden stratospheric warmings. Journal of Geophysical Research: Atmospheres, 117, D04101. URL: http://onlinelibrary.wiley.com/store/10.1029/2011JD016769/ asset/jgrd17642. pdf?v=1\&t=hux7gxx1\&s=a67470248062c314123c9e63c30d6064ca9eb5bd.

Bao, M., Tan, X., Hartmann, D. L. and Ceppi, P. (2017) Classifying the tropospheric precursor patterns of sudden stratospheric warmings. Geophysical Research Letters, 44, 8011-8016. URL: http://dx. doi .org/10. 1002/2017GL074611.

Barnes, E. A., Samarasinghe, S. M., Ebert-Uphoff, I. and Furtado, J. C. (2019) Tropospheric and Stratospheric Causal Pathways Between the MJO and NAO. Journal of Geophysical Research: Atmospheres, 124, 9356- 9371. URL: https: //doi .org/10. 1029/2019JD031024.

Barriopedro, D. and Calvo, N. (2014) On the Relationship between ENSO, Stratospheric Sudden Warmings, and Blocking. Journal of Climate, 27, 4704-4720. URL: http://journals. ametsoc.org/doi/abs/10.1175/JCLI-D-13-00770.1http:// journals. ametsoc.org/doi/pdf/10.1175/JCLI-D-13-00770.1.

Birner, T. and Albers, J. R. (2017) Sudden Stratospheric Warmings and Anomalous Upward Wave Activity Flux. SOLA, 13A, 8-12.

Butler, A., Charlton-Perez, A., Domeisen, D. I. V., Garfinkel, C., Gerber, E. P., Hitchcock, P., Karpechko, A. Y., Maycock, A. C., Sigmond, M., Simpson, I. and Son, S.-W. (2019) Chapter 11 - Sub-seasonal Predictability and the Stratosphere. In SubSeasonal to Seasonal Prediction (eds. A. W. Robertson and F. Vitart), 223-241. Elsevier. URL: http://www. sciencedirect . com/science/article/pii/B9780128117149000115.

Butler, A. H., Arribas, A., Athanassiadou, M., Baehr, J., Calvo, N., Charlton-Perez, A., Déqué, M., Domeisen, D. I. V., Fröhlich, K., Hendon, H., Imada, Y., Ishii, M., Iza, M., Karpechko, A. Y., Kumar, A., MacLachlan, C., Merryfield, W. J., Müller, W. A., O'Neill, A., Scaife, A. A., Scinocca, J., Sigmond, M., Stockdale, T. N. and Yasuda, T. (2016) The Climate-system Historical Forecast Project: Do stratosphere-resolving models make better seasonal climate predictions in boreal winter? Quarterly Journal of the Royal Meteorological Society, 142, 1413-1427. URL: http://dx.doi .org/10.1002/qj . 2743.

Butler, A. H., Sjoberg, J. P., Seidel, D. J. and Rosenlof, K. H. (2017) A sudden stratospheric warming compendium. Earth System Science Data, 9, 63-76. URL: https://www. earth-syst-sci-data.net/9/63/2017/.

de la Cámara, A., Birner, T. and Albers, J. R. (2019) Are sudden stratospheric warmings preceded by anomalous tropospheric wave activity? Journal of Climate, 32, 7173-7189. URL: https ://doi .org/10.1175/JCLI-D-19-0269.1.

Castanheira, J. M. and Barriopedro, D. (2010) Dynamical connection between tropospheric blockings and stratospheric polar vortex. Geophysical Research Letters, 37, L13809. URL: https : //doi .org/10.1029/2010GL043819.

Charlton, A. J. and Polvani, L. M. (2007) A new look at stratospheric sudden warmings. Part I: Climatology and modeling benchmarks. Journal of Climate, 20, 449-469.

Charney, J. G. and Drazin, P. G. (1961) Propagation of planetary-scale disturbances from the lower into the upper atmosphere. Journal of Geophysical Research, 66, 83-109. URL: http://onlinelibrary.wiley.com/doi/10.1029/JZ066i001p00083/ abstracthttp://onlinelibrary wiley.com/store/10.1029/JZ066i001p00083/asset/jgr2289. pdf? v=1\&t=hmv2kmmz\&s= Od9a140cc0c43368bd778a88ccadf c341689b634.

Cohen, J. and Jones, J. (2011) Tropospheric precursors and stratospheric warmings. Journal of Climate, 24, 6562-6572. URL: http://journals . ametsoc.org/doi/pdf/10.1175/2011JCLI4160.1http://web.mit.edu/j1cohen/www/ papers/CohenandJones_JC12.pdf.

Coy, L., Newman, P. A., Pawson, S. and Lait, L. R. (2017) Dynamics of the Disrupted 2015-16 Quasi-Biennial Oscillation. Journal of Climate, 30, 5661-5674. URL: http://dx.doi.org/10.1175/JCLI-D-16-0663.1. 
Dee, D. P., Uppala, S. M., Simmons, A. J., Berrisford, P., Poli, P., Kobayashi, S., Andrae, U., Balmaseda, M. A., Balsamo, G., Bauer, P., Bechtold, P., Beljaars, A. C. M., van de Berg, L., Bidlot, J., Bormann, N., Delsol, C., Dragani, R., Fuentes, M., Geer, A. J., Haimberger, L., Healy, S. B., Hersbach, H., Hólm, E. V., Isaksen, L., Kållberg, P., Köhler, M., Matricardi, M., McNally, A. P., Monge-Sanz, B. M., Morcrette, J.-J., Park, B.-K., Peubey, C., de Rosnay, P., Tavolato, C., Thépaut, J.-N. and Vitart, F. (2011) The ERA-Interim reanalysis: configuration and performance of the data assimilation system. Quarterly Journal of the Royal Meteorological Society, 137, 553-597. URL: http://onlinelibrary.wiley.com/doi/10.1002/qj.828/abstract.

Deser, C., Simpson, I. R., McKinnon, K. A. and Phillips, A. S. (2017) The Northern Hemisphere extra-tropical atmospheric circulation response to ENSO: How well do we know it and how do we evaluate models accordingly? Journal of Climate, 30, 5059-5082. URL: http://dx.doi.org/10.1175/JCLI-D-16-0844.1.

Domeisen, D. I. V., Butler, A. H., Charlton-Perez, A. J., Ayarzagüena, B., Baldwin, M. P., Dunn-Sigouin, E., Furtado, J. C., Garfinkel, C. I., Hitchcock, P., Karpechko, A. Y., Kim, H., Knight, J., Lang, A. L., Lim, E.-P., Marshall, A., Roff, G., Schwartz, C., Simpson, I. R., Son, S.-W. and Taguchi, M. (2020a) The role of the stratosphere in subseasonal to seasonal prediction Part II: Predictability arising from stratosphere - troposphere coupling. Journal of Geophysical Research: Atmospheres, 125, e2019JD030923. URL: https://doi.org/10.1029/2019JD030923.

- (2020b) The role of the stratosphere in subseasonal to seasonal prediction Part I: Predictability of the stratosphere. Journal of Geophysical Research: Atmospheres, 125, e2019JD030920. URL: https ://doi .org/10. 1029/2019JD030920.

Domeisen, D. I. V., Garfinkel, C. I. and Butler, A. H. (2019) The Teleconnection of El Niño Southern Oscillation to the Stratosphere. Reviews of Geophysics, 57, 5- 47. URL: https://agupubs.onlinelibrary.wiley.com/doi/abs/10.1029/ 2018 RG000596.

Esler, J. G. and Scott, R. K. (2005) Excitation of Transient Rossby Waves on the Stratospheric Polar Vortex and the Barotropic Sudden Warming. Journal of the Atmospheric Sciences, 62, 3661-3682. URL: https://doi .org/10.1175/JAS3557.1.

Fletcher, C. G. and Kushner, P. J. (2013) Linear interference and the northern annular mode response to tropical SST forcing: Sensitivity to model configuration. Journal of Geophysical Research: Atmospheres, 118, 42674279. URL: http://onlinelibrary $\cdot$ wiley.com/store/10.1002/jgrd $.50385 /$ asset/jgrd50385.pdf?v=1\&t=hf5qrdqr\&s= 443de1557f0ddbcabb740a81a399b5cec1dfb14f.

Fraedrich, K., Pawson, S. and Wang, R. (1993) An EOF Analysis of the Vertical-Time Delay Structure of the Quasi-Biennial Oscillation. Journal of the Atmospheric Sciences, 50, 3357-3365. URL: https://doi .org/10.1175/1520-0469(1993)050\% 3C3357: AEAOTV\%3E2.0. COhttp://0.0.0.2.

Garfinkel, C. I., Benedict, J. J. and Maloney, E. D. (2014) Impact of the MJO on the boreal winter extratropical circulation. Geophysical Research Letters, 41, 6055-6062. URL: http://dx. doi .org/10.1002/2014GL061094.

Garfinkel, C. I., Feldstein, S. B., Waugh, D. W., Yoo, C. and Lee, S. (2012a) Observed connection between stratospheric sudden warmings and the Madden-Julian Oscillation. Geophysical Research Letters, 39. URL: http://doi.wiley.com/10.1029/ 2012 GL053144.

Garfinkel, C. I., Hartmann, D. L. and Sassi, F. (2010) Tropospheric precursors of anomalous Northern Hemisphere stratospheric polar vortices. Journal of Climate, 23, 3282-3299. URL: http://journals . ametsoc .org/doi/pdf/10.1175/2010JCLI3010. 1.

Garfinkel, C. I., Schwartz, C., Domeisen, D. I. V., Son, S.-W., Butler, A. H. and White, I. P. (2018) Extratropical Atmospheric Predictability From the Quasi-Biennial Oscillation in Subseasonal Forecast Models. Journal of Geophysical Research: Atmospheres, 123, 7855-7866. URL: https ://agupubs . onlinelibrary . wiley . com/doi/abs/10. 1029/2018JD028724.

Garfinkel, C. I., Shaw, T. a., Hartmann, D. L. and Waugh, D. W. (2012b) Does the Holton-Tan Mechanism Explain How the Quasi-Biennial Oscillation Modulates the Arctic Polar Vortex? Journal of the Atmospheric Sciences, 69, 1713-1733. URL: http://journals. ametsoc .org/doi/abs/10.1175/JAS-D-11-0209.1. 
Gerber, E. P. and Martineau, P. (2018) Quantifying the variability of the annular modes: reanalysis uncertainty vs. sampling uncertainty. Atmospheric Chemistry and Physics, 18, 17099-17117. URL: https://www . atmos-chem-phys .net/18/17099/ 2018/.

Greening, K. and Hodgson, A. (2019) Atmospheric analysis of the cold late February and early March 2018 over the UK. Weather, 74, 79-85. URL: https://rmets .onlinelibrary.wiley.com/doi/abs/10.1002/wea.3467.

Henderson, S. A., Maloney, E. D. and Barnes, E. A. (2016) The Influence of the Madden-Julian Oscillation on Northern Hemisphere Winter Blocking. Journal of Climate, 29, 4597-4616. URL: http://journals . ametsoc .org/doi/abs/10.1175/JCLID-15-0502.1.

Holton, J. R. and Tan, H.-C. (1980) The Influence of the Equatorial Quasi-Biennial Oscillation on the Global Circulation at 50 mb. Journal of the Atmospheric Sciences, 37, 2200-2208. URL: http://dx. doi.org/10.1175/1520-0469(1980) 037<2200: TIOTEQ> 2.0.CO2.

Hoskins, B. J. and Karoly, D. J. (1981) The Steady Linear Response of a Spherical Atmosphere to Thermal and Orographic Forcing. Journal of the Atmospheric Sciences, 38, 1179-1196. URL: http: //journals . ametsoc .org/doi/abs/10.1175/15200469 (1981) $038<1179$ : TSLROA $>2.0$. CO 2 .

Kang, W. and Tziperman, E. (2017) More frequent Sudden Stratospheric Warming events due to enhanced MJO forcing expected in a warmer climate. Journal of Climate, 30, 8727-8743. URL: https ://doi .org/10.1175/JCLI-D-17-0044.1.

Karpechko, A., Charlton-Perez, A., Balmaseda, M., Tyrrell, N. and Vitart, F. (2018) Predicting Sudden Stratospheric Warming 2018 and its Climate Impacts with a Multi-Model Ensemble. Geophysical Research Letters, 45, 13,538- 13,546. URL: https://agupubs . onlinelibrary · wiley.com/doi/abs/10.1029/2018GL081091.

Karpechko, A. Y. (2018) Predictability of Sudden Stratospheric Warmings in the ECMWF Extended-Range Forecast System. Monthly Weather Review, 146, 1063-1075. URL: https : //doi .org/10.1175/MWR-D-17-0317.1.

Karpechko, A. Y., Hitchcock, P., Peters, D. H. W. and Schneidereit, A. (2017) Predictability of downward propagation of major sudden stratospheric warmings. Quarterly Journal of the Royal Meteorological Society, 143, 1459-1470. URL: http://dx. doi.org/10.1002/qj.3017.

Lawrence, Z. D. and Manney, G. L. (2018) Characterizing Stratospheric Polar Vortex Variability With Computer Vision Techniques. Journal of Geophysical Research: Atmospheres, 123, 1510-1535. URL: http://dx.doi .org/10.1002/2017JD027556.

- (2020) Does the Arctic stratospheric polar vortex exhibit signs of preconditioning prior to sudden stratospheric warmings? Journal of the Atmospheric Sciences, 77, 611-632. URL: https://doi .org/10.1175/JAS-D-19-0168.1.

Lee, S. H. and Butler, A. H. (2019) The 2018-2019 Arctic stratospheric polar vortex. Weather, 75, 52-57. URL: https: //doi.org/10.1002/wea. 3643.

Lee, S. H., Charlton-Perez, A. J., Furtado, J. C. and Woolnough, S. J. (2019) Abrupt stratospheric vortex weakening associated with North Atlantic anticyclonic wave breaking. Journal of Geophysical Research: Atmospheres, 124, 8563- 8575. URL: https://doi.org/10.1029/2019JD030940.

Lim, Y., Son, S.-W. and Kim, D. (2018) MJO prediction skill of the subseasonal-to-seasonal prediction models. Journal of Climate, 31, 4075-4094. URL: https : //doi.org/10.1175/JCLI-D-17-0545.1.

Lin, H., Brunet, G. and Derome, J. (2009) An Observed Connection between the North Atlantic Oscillation and the Madden-Julian Oscillation. Journal of Climate, 22, 364-380. URL: http://journals.ametsoc.org/doi/abs/10.1175/ 2008JCLI2515. 1.

Liu, C., Tian, B., Li, K.-F., Manney, G. L., Livesey, N. J., Yung, Y. and Waliser, D. E. (2014) Northern Hemisphere mid-winter vortex-displacement and vortex-split stratospheric sudden warmings: Influence of the Madden-Julian Oscillation and Quasi-Biennial Oscillation. Journal of Geophysical Research: Atmospheres, 2014JD021876. URL: http://dx.doi.org/10. 1002/2014JD021876. 
Lu, H., Hitchman, M. H., Gray, L. J., Anstey, J. A. and Osprey, S. M. (2020) On the Role of Rossby Wave Breaking in the QuasiBiennial Modulation of the Stratospheric Polar Vortex during Boreal Winter. Quarterly Journal of the Royal Meteorological Society, 1- 21. URL: https://doi.org/10.1002/qj.3775.

Martius, O., Polvani, L. M. and Davies, H. C. (2009) Blocking precursors to stratospheric sudden warming events. Geophysical Research Letters, 36, L14806. URL: http://doi.wiley.com/10.1029/2009GL038776.

Matthewman, N. J., Esler, J. G., Charlton-Perez, A. J. and Polvani, L. M. (2009) A New Look at Stratospheric Sudden Warmings. Part III: Polar Vortex Evolution and Vertical Structure. Journal of Climate, 22, 1566-1585. URL: http: //journals . ametsoc. org/doi/abs/10.1175/2008JCLI2365.1.

Mitchell, D. M., Gray, L. J., Anstey, J., Baldwin, M. P. and Charlton-Perez, A. J. (2013) The Influence of Stratospheric Vortex Displacements and Splits on Surface Climate. Journal of Climate, 26, 2668-2682. URL: http://journals.ametsoc.org/ doi/abs/10.1175/JCLI-D-12-00030.1.

Peings, Y. (2019) Ural Blocking as a driver of early winter stratospheric warmings. Geophysical Research Letters, 46, 54605468. URL: https://agupubs.onlinelibrary.wiley.com/doi/abs/10.1029/2019GL082097.

Rao, J., Garfinkel, C. I., Chen, H. and White, I. P. (2019) The 2019 New Year Stratospheric Sudden Warming and Its Real-Time Predictions in Multiple S2S Models. Journal of Geophysical Research: Atmospheres, 124. URL: https://doi.org/10.1029/ 2019JD030826.

Rao, J., Garfinkel, C. I. and White, I. P. (2020) Predicting the Downward and Surface Influence of the February 2018 and January 2019 Sudden Stratospheric Warming Events in Subseasonal to Seasonal (S2S) Models. Journal of Geophysical Research: Atmospheres, 125, e2019JD031919. URL: https://doi.org/10.1029/2019JD031919.

Rao, J., Ren, R., Chen, H., Yu, Y. and Zhou, Y. (2018) The Stratospheric Sudden Warming Event in February 2018 and its Prediction by a Climate System Model. Journal of Geophysical Research: Atmospheres, 123, 313-332. URL: https:// agupubs .onlinelibrary.wiley.com/doi/abs/10.1029/2018JD028908.

Rashid, H. A., Hendon, H. H., Wheeler, M. C. and Alves, O. (2011) Prediction of the Madden-Julian oscillation with the POAMA dynamical prediction system. Climate Dynamics, 36, 649-661. URL: https ://doi .org/10.1007/s00382-010-0754-x.

Saha, S., Moorthi, S., Wu, X., Wang, J., Nadiga, S., Tripp, P., Behringer, D., Hou, Y.-T., Chuang, H.-y., Iredell, M., Ek, M., Meng, J., Yang, R., Peña Mendez, M., van den Dool, H., Zhang, Q., Wang, W., Chen, M. and Becker, E. (2014) The NCEP Climate Forecast System Version 2. Journal of Climate, 27, 2185-2208. URL: http://journals.ametsoc.org/doi/abs/10.1175/ JCLI-D-12-00823.1?af=R.

Seviour, W. J. M., Mitchell, D. M. and Gray, L. J. (2013) A practical method to identify displaced and split stratospheric polar vortex events. Geophysical Research Letters, 40, 5268-5273. URL: http://onlinelibrary.wiley.com/doi/10.1002/grl. 50927 /abstract.

Shi, C., Xu, T., Guo, D. and Pan, Z. (2017) Modulating Effects of Planetary Wave 3 on a Stratospheric Sudden Warming Event in 2005. Journal of the Atmospheric Sciences, 74, 1549-1559. URL: https ://doi .org/10.1175/JAS-D-16-0065.1.

Smith, A. K. (1983) Observation of Wave-Wave Interactions in the Stratosphere. Journal of the Atmospheric Sciences, 40, 2484-2496. URL: https://doi.org/10.1175/1520-0469(1983)040\%3C2484:00WWII\%3E2.0.cohttp://0.0.0.2.

Smith, K. L. and Kushner, P. J. (2012) Linear interference and the initiation of extratropical stratosphere-troposphere interactions. Journal of Geophysical Research-Atmospheres, 117.

Taguchi, M. (2015) Connection of predictability of major stratospheric sudden warmings to polar vortex geometry. Atmospheric Science Letters, 17, 33-38. URL: http://dx.doi.org/10.1002/asl.595.

- (2018) Comparison of Subseasonal-to-Seasonal Model Forecasts for Major Stratospheric Sudden Warmings. Journal of Geophysical Research: Atmospheres, 123, 210-231. URL: https://agupubs.onlinelibrary.wiley.com/doi/abs/10.1029/ 2018JD028755. 
Tripathi, O. P., Baldwin, M., Charlton-Perez, A., Charron, M., Eckermann, S. D., Gerber, E., Harrison, R. G., Jackson, D. R., Kim, B.-M., Kuroda, Y., Lang, A., Mahmood, S., Mizuta, R., Roff, G., Sigmond, M. and Son, S.-W. (2014) The predictability of the extratropical stratosphere on monthly time-scales and its impact on the skill of tropospheric forecasts. Quarterly Journal of the Royal Meteorological Society, 987-1003. URL: http://dx.doi .org/10.1002/qj .2432.

Vitart, F. (2017) Madden-Julian Oscillation Prediction and Teleconnections in the S2S Database. Quarterly Journal of the Royal Meteorological Society, 143, 2210-2220. URL: http://dx.doi .org/10.1002/qj .3079.

Vitart, F., Ardilouze, C., Bonet, A., Brookshaw, A., Chen, M., Codorean, C., Déqué, M., Ferranti, L., Fucile, E., Fuentes, M., Hendon, H., Hodgson, J., Kang, H. S., Kumar, A., Lin, H., Liu, G., Liu, X., Malguzzi, P., Mallas, I., Manoussakis, M., Mastrangelo, D., MacLachlan, C., McLean, P., Minami, A., Mladek, R., Nakazawa, T., Najm, S., Nie, Y., Rixen, M., Robertson, A. W., Ruti, P., Sun, C., Takaya, Y., Tolstykh, M., Venuti, F., Waliser, D., Woolnough, S., Wu, T., Won, D.-J., Xiao, H., Zaripov, R. and Zhang, L. (2017) The Sub-seasonal to Seasonal Prediction (S2S) Project Database. Bulletin of the American Meteorological Society, 98, 162-173. URL: http://dx.doi.org/10.1175/BAMS-D-16-0017.1.

Wang, R., Fraedrich, K. and Pawson, S. (1995) Phase-Space Characteristics of the Tropical Stratospheric Quasi-Biennial Oscillation. Journal of the Atmospheric Sciences, 52, 4482-4500. URL: https : //doi .org/10.1175/1520-0469 (1995) 052\%3C4482: PCOTTS\%3E2.0. Cohttp://0.0.0.2.

Wheeler, M. C. and Hendon, H. H. (2004) An All-Season Real-Time Multivariate MJO Index: Development of an Index for Monitoring and Prediction. Monthly Weather Review, 132, 1917-1932. URL: https: //doi .org/10.1175/1520-0493 (2004) 132\%3C1917: AARMMI\%3E2.0. COhttp://0.0.0.2.

White, I., Garfinkel, C. I., Gerber, E. P., Jucker, M., Aquila, V. and Oman, L. D. (2019) The Downward Influence of Sudden Stratospheric Warmings: Association with Tropospheric Precursors. Journal of Climate, 32, 85-108. URL: https://doi. org/10.1175/JCLI-D-18-0053.1.

White, I. P., Lu, H., Mitchell, N. J. and Phillips, T. (2015) Dynamical Response to the QBO in the Northern Winter Stratosphere: Signatures in Wave Forcing and Eddy Fluxes of Potential Vorticity. Journal of the Atmospheric Sciences, 72, 4487-4507. URL: http://dx.doi.org/10.1175/JAS-D-14-0358.1.

Woollings, T., Charlton-Perez, A., Ineson, S., Marshall, A. G. and Masato, G. (2010) Associations between stratospheric variability and tropospheric blocking. Journal of Geophysical Research: Atmospheres, 115. URL: https://doi.org/10.1029/ 2009JD012742. 


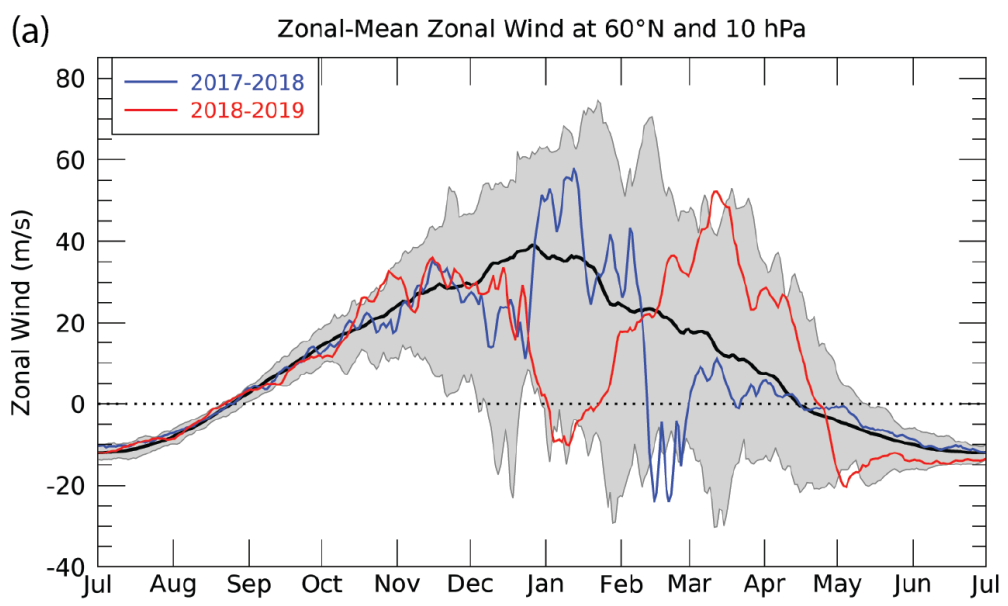

(b) 2018: February 7-14

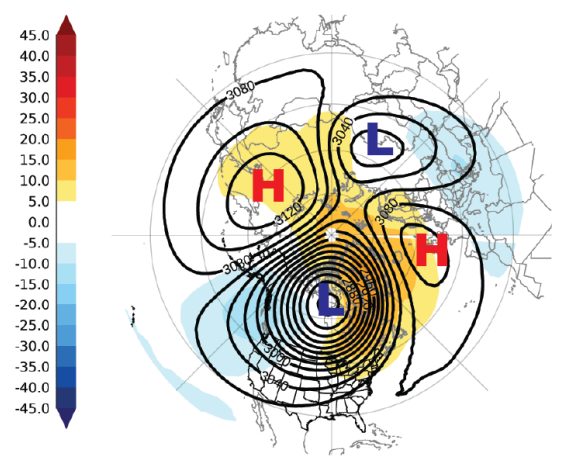

(c) 2019: January 2-9

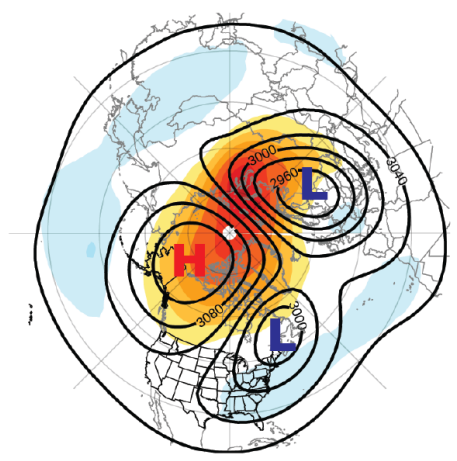

FIGURE 1 (a) Time series of the ERA-Interim $10 \mathrm{hPa} 60^{\circ} \mathrm{N}$ zonal-mean zonal winds for 2017-2018 (blue line) and 2018-2019 (red line) overlying the daily mean (black line) and daily maximum and minimum (grey shading). The daily statistics are based on the 1979-2017 record. Averaged $10 \mathrm{hPa}$ geopotential heights [dam] (contour) and 10 hPa temperature anomalies [K] (shading) for the (b) 7-14 February 2018, and the (c) 2-9 January 2019 period. 


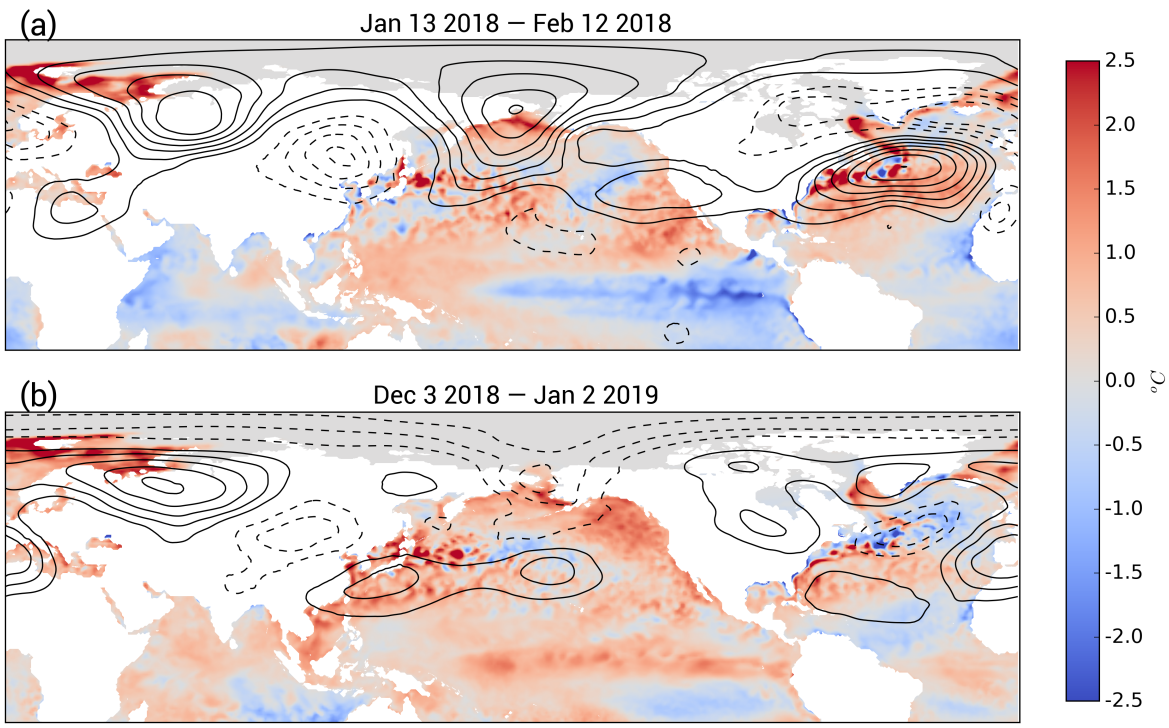

FIGURE 2 Sea surface temperature anomalies (shading, [degrees C]) and $500 \mathrm{hPa}$ geopotential height anomalies (contoured every $30 \mathrm{~m}$, omitting the 0 contour) from ERA-interim for 30 days preceding the vortex split on (a) 12 February 2018 and (b) 2 January 2019.
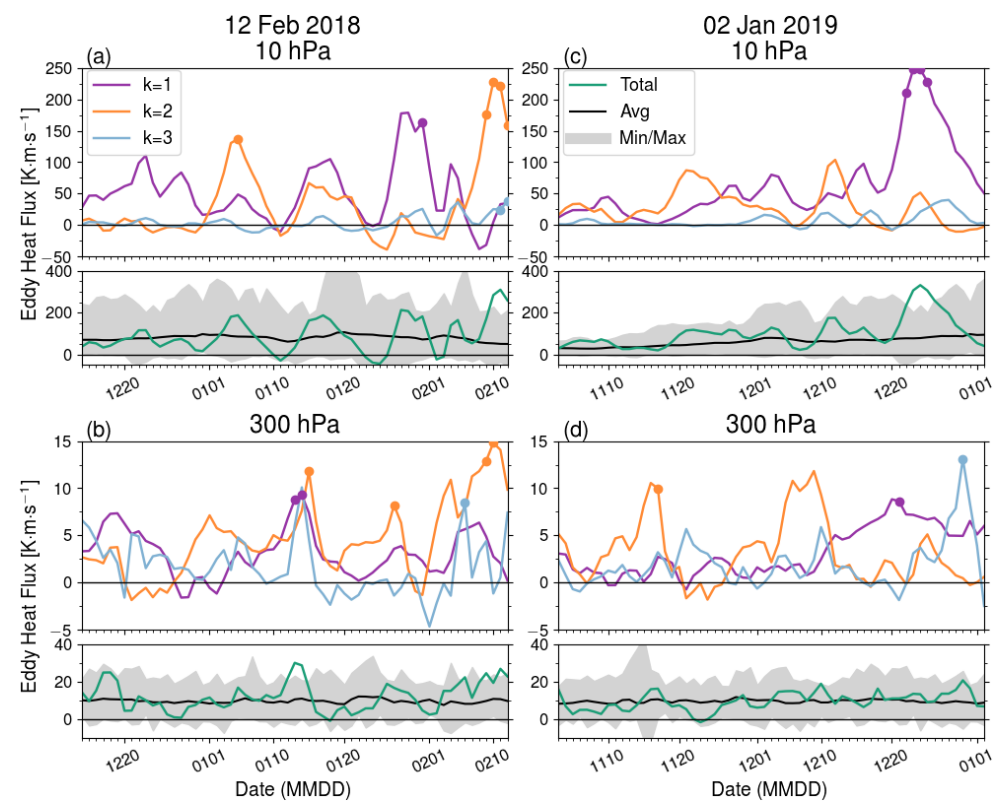

FIGURE 3 Time series of $40-80^{\circ} \mathrm{N}$ averaged eddy heat flux due to wavenumbers $k=1,2$, and 3 on top of total eddy heat fluxes (green line) and their daily climatological extremes for the 1979-2017 period (gray shading) for 60 days before (a,b) the 2018 event and (c,d) the 2019 event, for (a,c) $10 \mathrm{hPa}$ and (b,d) $300 \mathrm{hPa}$. Times when the wave-component heat fluxes are maxima in the ERA-Interim record are denoted with dots. 


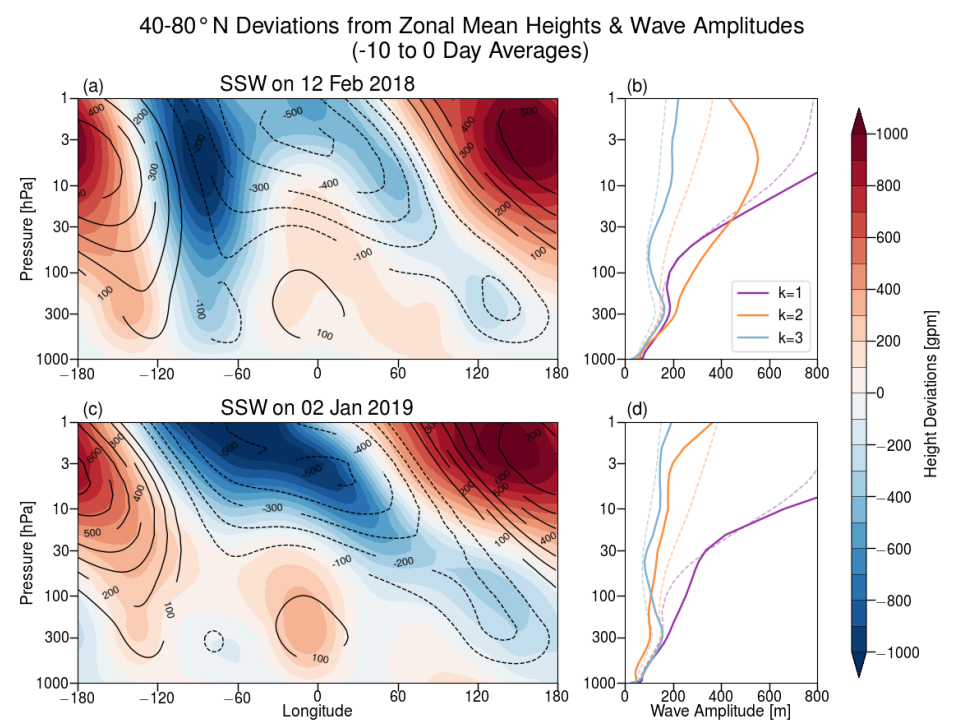

F IG URE 4 (a,c) Longitude by height cross-sections of $40-80^{\circ} \mathrm{N}$ deviations from zonal mean geopotential heights, and $(b, d)$ the corresponding wave amplitudes for wavenumbers $k=1-3$, composited over days -10 to 0 prior to the (a,b) 2018 SSW and (c,d) 2019 SSW. In (a,c), the climatological height deviations from zonal mean for the same days are shown by black contours. In (b,d) the climatological wave amplitudes are shown by light dashed lines.

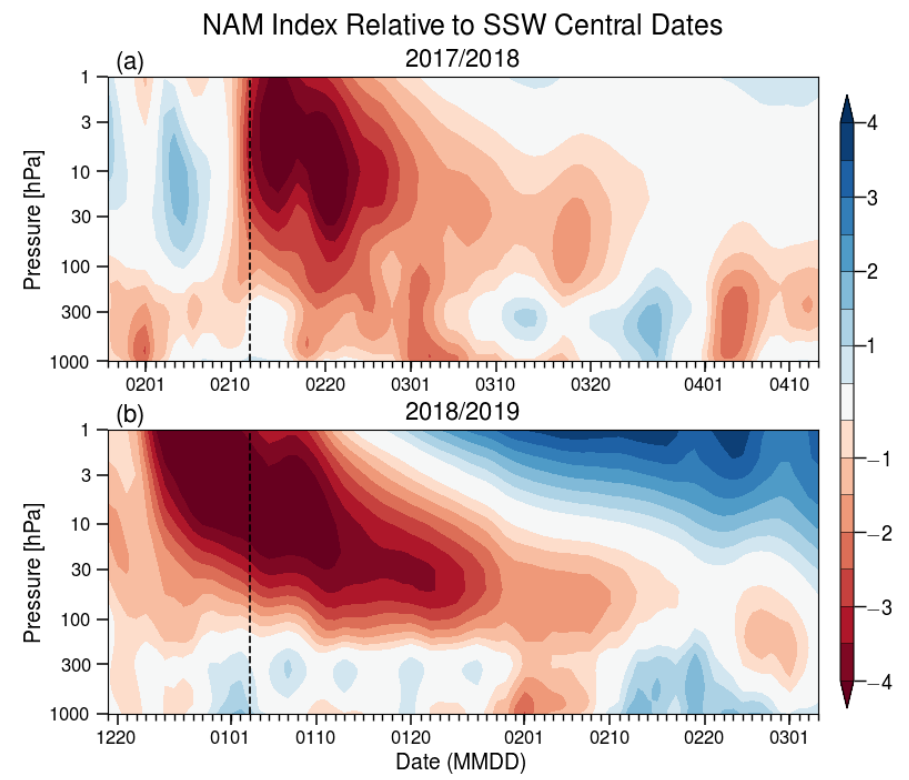

FIGURE 5 Time series of the Northern Annular Mode index as a function of pressure, for 15 days before and 60 days following the (a) 12 February 2018 and (b) 2 January 2019 sudden warming events. 

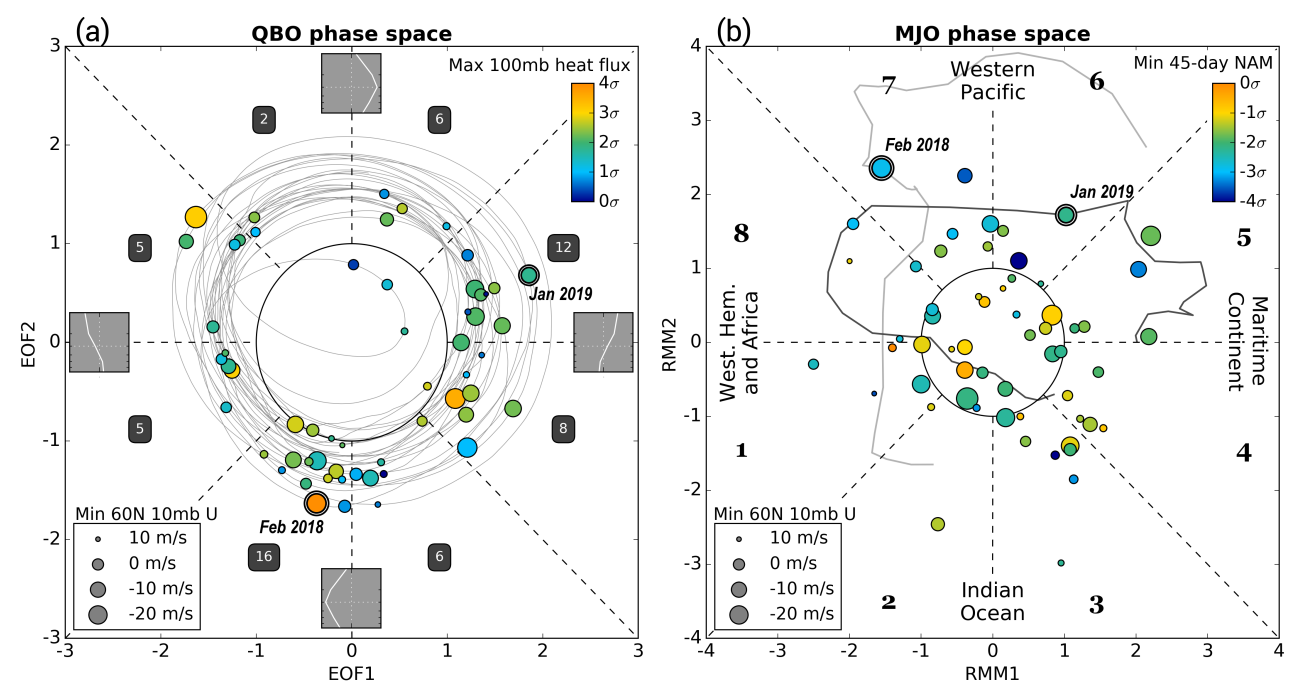

FIGURE 6 a) QBO phase space, with grey lines tracing the historical QBO and colored dots representing vortex weakening events (using ERA-40 reanalysis from 1960-1979, ERA-Interim from 1979-2019). The marker size corresponds to the magnitude of zonal-mean zonal wind reversal at $10 \mathrm{hPa}$ and $60^{\circ} \mathrm{N}$, and the color corresponds to the maximum $100 \mathrm{hPa} 45-75^{\circ} \mathrm{N}$ eddy heat flux anomaly in the 10 days prior to each vortex event. For visualization, the grey box every 90 degrees shows the vertical profile of tropical $\left(5^{\circ} \mathrm{S}-5^{\circ} \mathrm{N}\right)$ zonal-mean zonal winds, as a function of pressure, for that location in phase space. The horizontal white dashed line in the box represents $30 \mathrm{hPa}$. The number of vortex weakening events in each octant of the QBO phase space is provided in a dark grey box. b) State of the RMM index for the two events as compared with vortex weakening events since 1979 (based on ERA-Interim only), with the marker size corresponding to intensity and the color corresponding to the minimum $1000 \mathrm{hPa}$ NAM value in the 45 days following the vortex events. Gray lines trace the MJO for 15 days prior to 15 days after the 12 February 2018 SSW (light gray) and 2 January 2019 SSW (dark gray). 
(a) 12 February 2018 SSW: accurate predictions (first reversal within \pm 3 days)

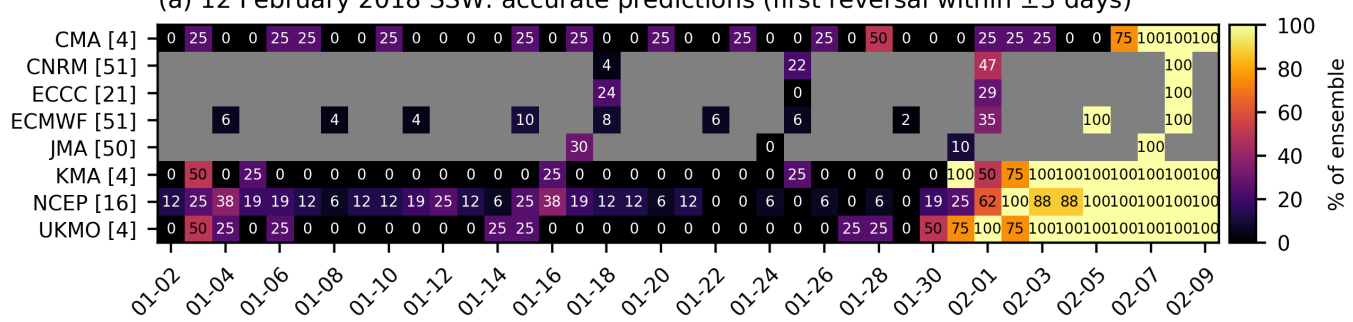

(b) 12 February 2018 SSW: false alarms (first reversal outside \pm 3 days)

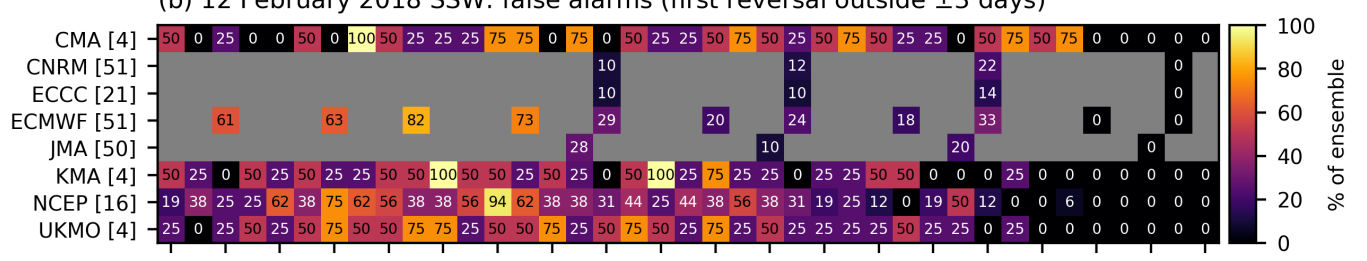

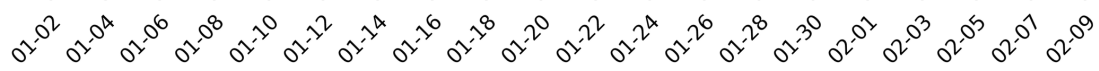

(c) 2 January 2019 SSW: accurate predictions (first reversal within \pm 3 days)

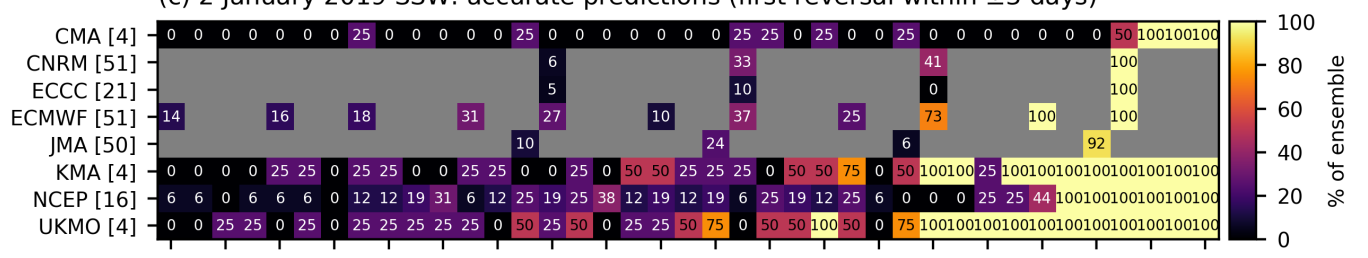

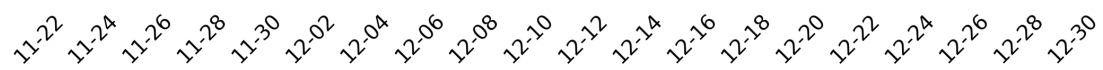

(d) 2 January 2019 SSW: false alarms (first reversal outside \pm 3 days)

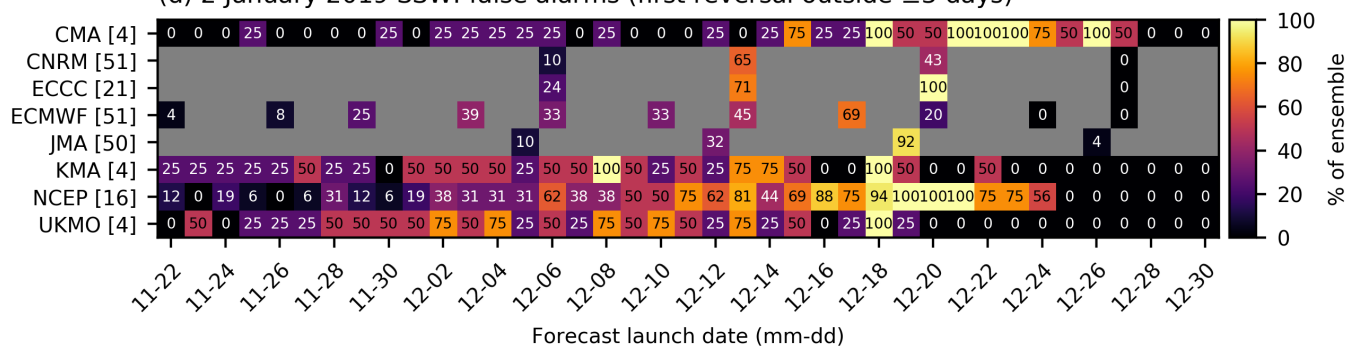

FIGURE 7 Percent of bias-corrected ensemble members from prediction systems participating in the S2S database that $(\mathrm{a}, \mathrm{c})$ correctly detected the first zonal wind reversal at $10 \mathrm{hPa}$ and $60^{\circ} \mathrm{N}$ within \pm 3 days of the observed event, and (b,d) detected the first zonal wind reversal at $10 \mathrm{hPa}$ and $60^{\circ} \mathrm{N}$ outside the \pm 3 day window, for the (a,b) 2018 SSW and the (c,d) 2019 SSW. 

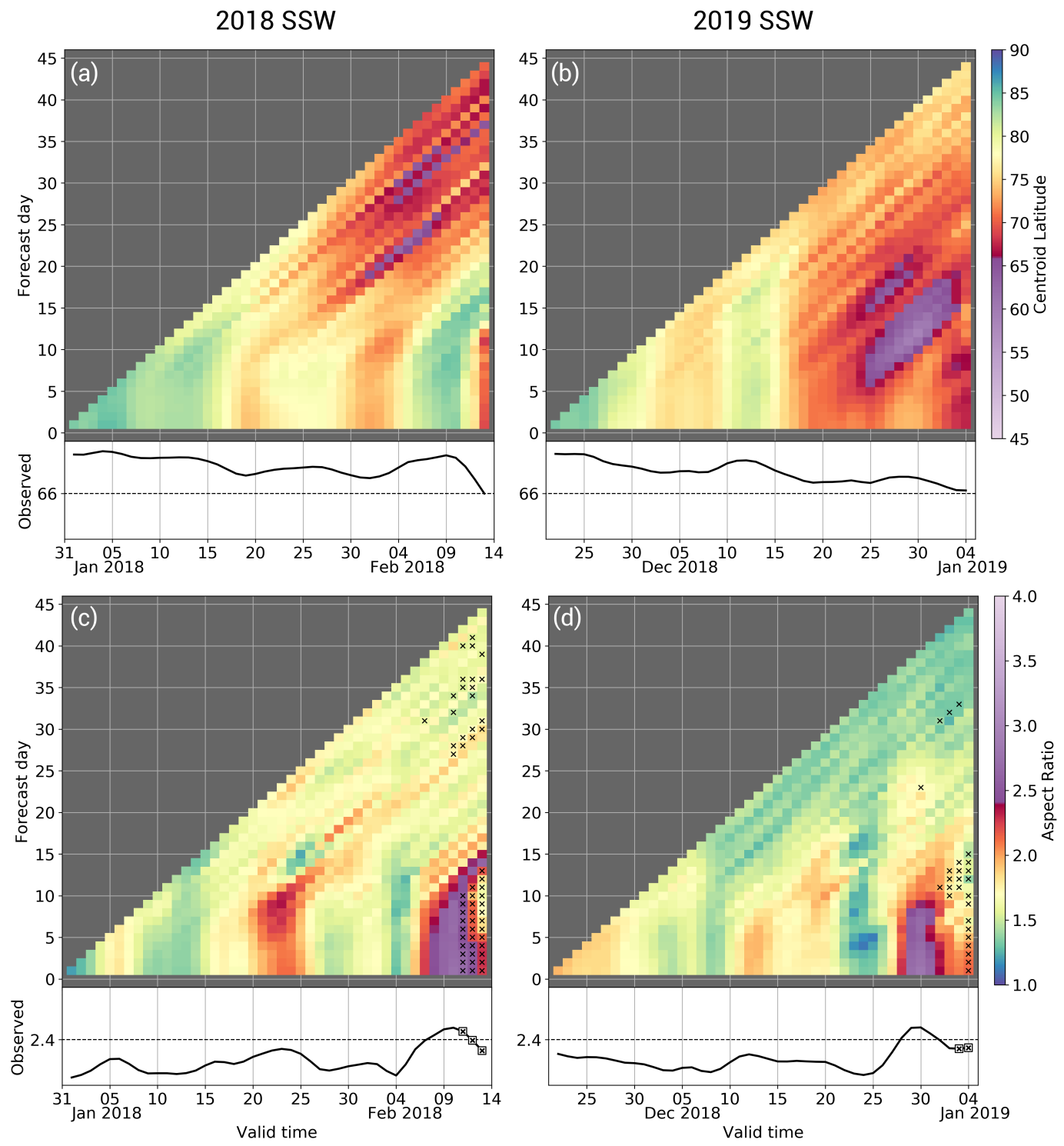

FIGURE 8 NCEP CFSv2 forecasts, as a function of initialization date ( $x$-axis) and forecast day ( $y$-axis), of (a,b) the vortex centroid latitude and (c,d) the aspect ratio, for the (a,c) 2018 SSW and the (b,d) 2019 SSW. The ERA-Interim moment diagnostics for each day are shown beneath each chiclet plot. The vortex can be said to be "displaced" when the centroid latitude is less than 66 degrees latitude, and to be "split" when the aspect ratio is greater than 2.4. The x's indicate where a region segmentation algorithm detected more than 1 distinct vortex region in ERA-Interim, or where the algorithm detected splits in more than half of the CFSv2 ensemble members. 
(a) Feb 2018 SSW: 22 Feb - 14 Mar 1000 hPa NAM error

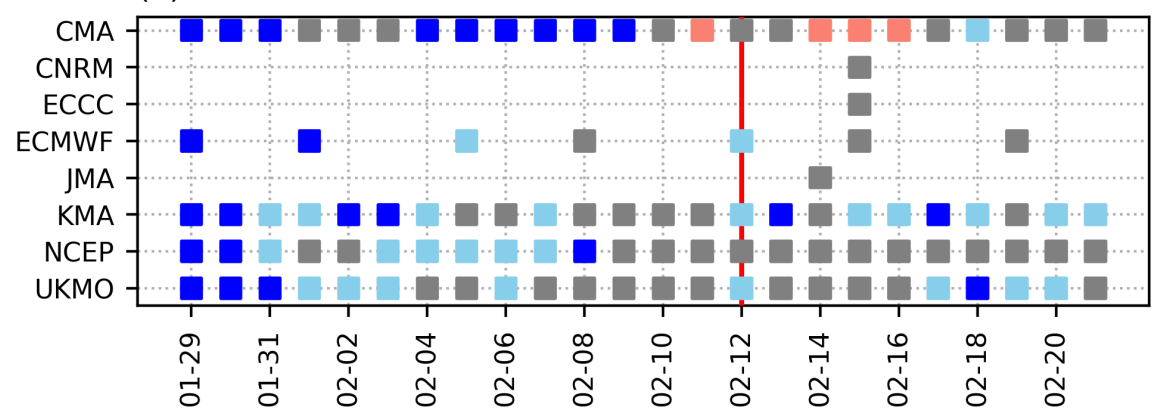

(b) Jan 2019 SSW: 12 Jan - 1 Feb 1000 hPa NAM error

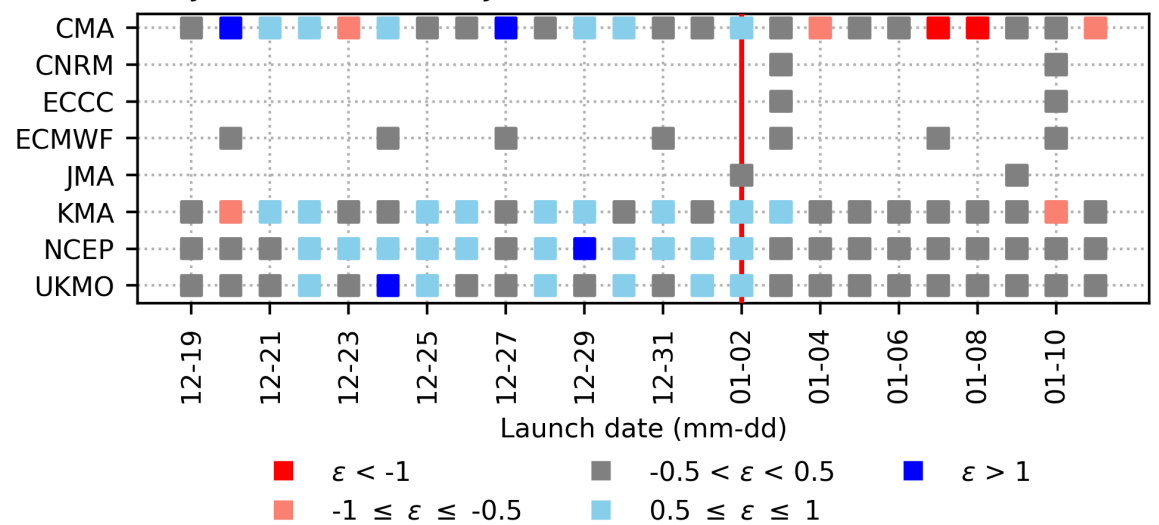

FIGURE 9 Difference between S2S ensemble mean forecasts for the average $1000 \mathrm{hPa}$ NAM for 10-30 days following the 2018 and 2019 SSWs and verification from ERA-Interim. In (a) this is for the period 22 February-14 March, in (b) this is 12 January-1 February. Gray indicates the magnitude of the difference to the observed value was $<0.5$, light red (light blue) indicates the forecast NAM was 0.5-1.0 standard deviations more negative (positive) than verification, and red (blue) indicates this difference exceeded 1 standard deviation. The vertical red line in each panel indicates the date of the SSW. 
(a) $2018 \mathrm{SSW}$

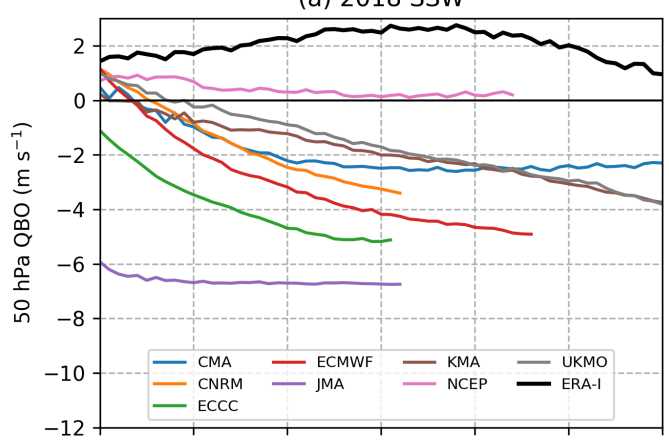

(c) $2019 \mathrm{SSW}$

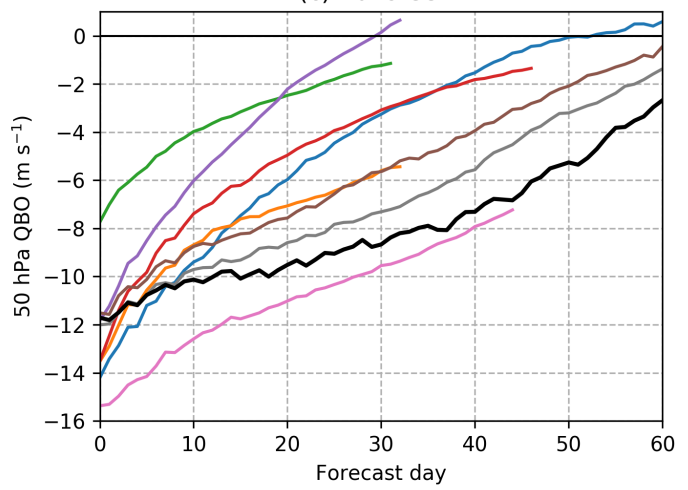

(b) $2018 \mathrm{SSW}$

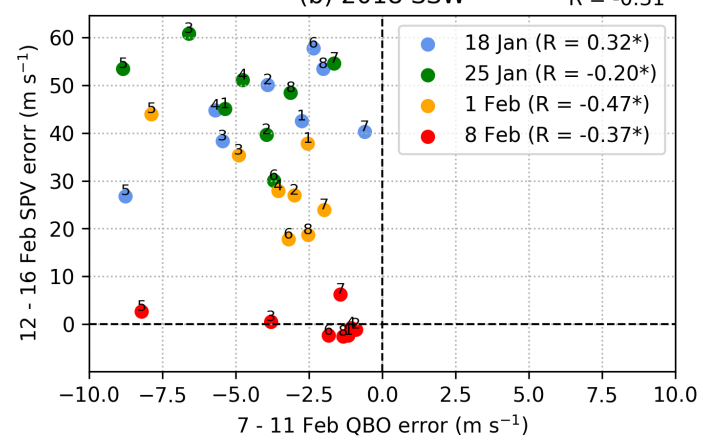

(d) $2019 \mathrm{SSW}$

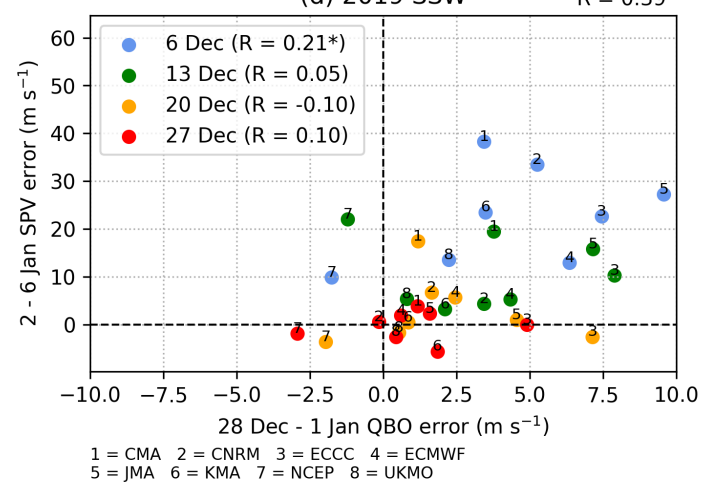

FIGURE 10 Tropical zonal-mean zonal winds averaged from $5^{\circ} \mathrm{N}-5^{\circ} \mathrm{S}$ at $50 \mathrm{hPa}$ prior to (a) $2018 \mathrm{SSW}$ and (b) 2019 SSW. These values are created by averaging forecasts over 4 launch dates consistent across prediction systems: 18 Jan, 25 Jan, 1 Feb, and 8 Feb 2018; and 6 Dec, 13 Dec, 20 Dec, and 27 Dec 2018 (note: JMA launches a day earlier). The black-line is ERA-Interim sub-sampled and averaged in an identical manner. Scatterplots of the averaged error in the QBO forecasts versus error in the zonal-mean zonal winds at $60^{\circ} \mathrm{N}$ and $10 \mathrm{hPa}(\mathrm{SPV})$, for (b) 2018: QBO 7-11 Feb (8-11 Feb for 8 Feb launch date, except ECCC 9-11 Feb), SPV 12-16 Feb, and (d) 2019: QBO 28 Dec-1 Jan, SPV 2-6 Jan [i.e. 5 days before/after SSW]. Correlation values are calculated using the multi-model ensemble of 201 members. Only ensemble-mean values are shown. In all panels, these are hindcast bias-corrected. An asterisk indicates the correlation is significant at the $95 \%$ confidence level according to a bootstrap re-sampling test $(10,000$ repeats). 
(a) $2018 \mathrm{SSW}$

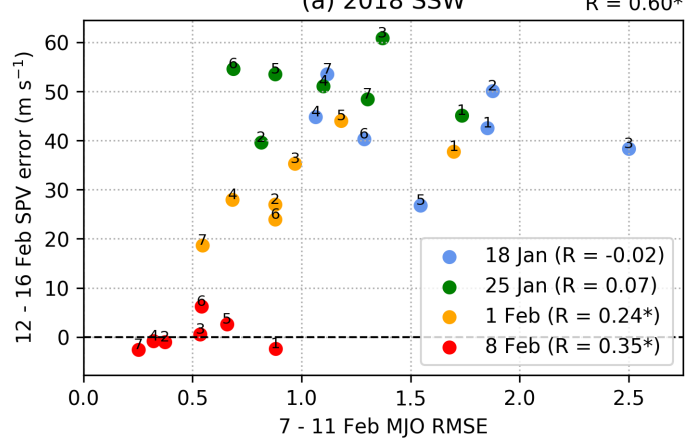

(c) $2019 \mathrm{SSW}$

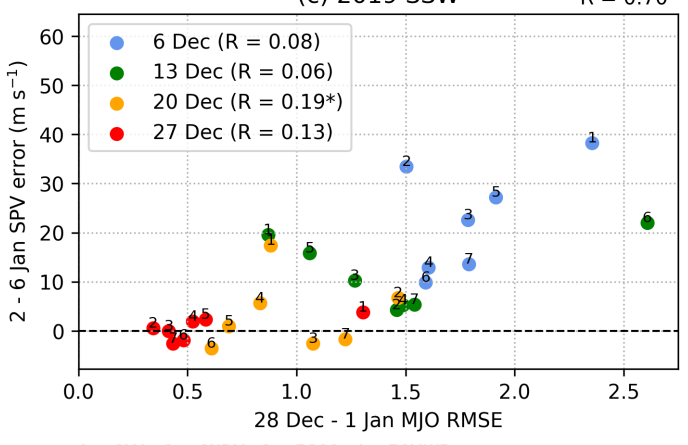

$1=\mathrm{CMA} \quad 2=\mathrm{CNRM} \quad 3=\mathrm{ECCC} \quad 4=\mathrm{ECMWF}$ $5=$ JMA $6=$ NCEP $7=$ UKMO

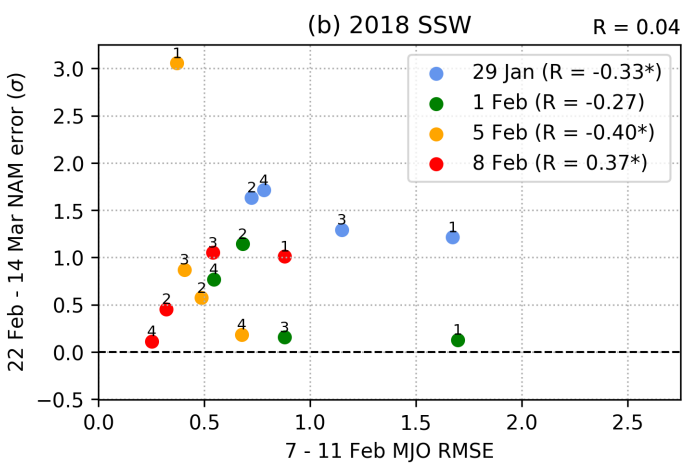

(d) $2019 \mathrm{SSW}$

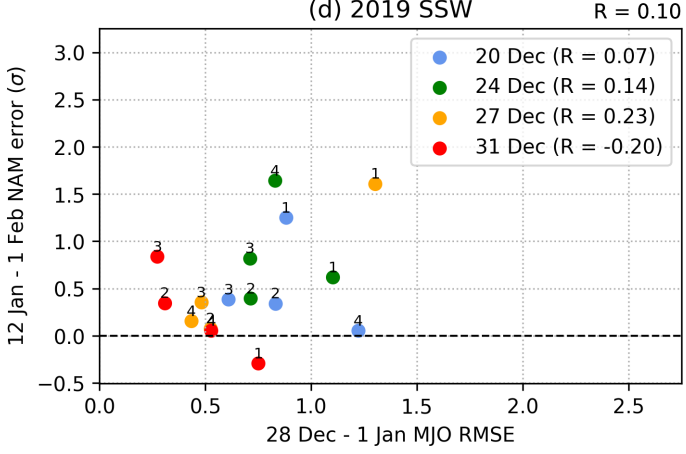

$1=$ CMA $2=$ ECMWF $3=$ NCEP $4=$ UKMO

FIGURE 11 Scatterplots of the averaged bivariate RMSE in the MJO forecasts for the 5 days before each SSW [(a, b) 7 - 11 Feb (8 - 11 Feb for 8 Feb launch date except ECCC 9 - 11 Feb), (c, d) 28 Dec - 1 Jan] versus (a, c) error in the zonal-mean zonal winds at $60^{\circ} \mathrm{N}$ and $10 \mathrm{hPa}$ (SPV) 5 days after the SSW and (b, d) error in the $1000 \mathrm{hPa}$ NAM 10-30 days after the SSW (as in Figure 9). Correlation values are calculated using the multi-model ensemble of $(a, c)$ 201 and (b,d) 75 members. Only ensemble-mean values are shown. In all panels, these are hindcast bias corrected. An asterisk indicates the correlation is significant at the $95 \%$ confidence level according to a bootstrap re-sampling test (10,000 repeats). 